\title{
Web Crippling Tests of Cold-formed Steel Channels under Two Flange Load Cases
}

\author{
S. Gunalan \\ Science and Engineering Faculty, Queensland University of Technology \\ Brisbane, QLD, 4000, Australia. \\ M. Mahendran \\ Science and Engineering Faculty, Queensland University of Technology \\ Brisbane, QLD, 4000, Australia.
}

\begin{abstract}
:
Cold-formed steel members have many advantages over hot-rolled steel members. However, they are susceptible to various buckling modes at stresses below the yield stress of the member because of their relatively high width-to-thickness ratio. Web crippling is a form of localized failure mode that can occur when the members are subjected to transverse high concentrated loadings and/or reactions. The four common loading conditions are the end-oneflange (EOF), interior-one-flange (IOF), end-two-flange (ETF) and interior-two-flange (ITF) loadings. Recently a test method has been proposed by AISI to obtain the web crippling capacities under these four loading conditions. Using this test method 42 tests were conducted in this research to investigate the web crippling behaviour and strengths of unlipped channels with stocky webs under ETF and ITF cases. DuraGal sections having a nominal yield stress of $450 \mathrm{MPa}$ were tested with different web slenderness and bearing lengths. The flanges of these channel sections were not fastened to the supports. In this research the suitability of the currently available design rules for unlipped channels subject to web crippling was investigated, and suitable modifications were proposed where necessary. In addition to this, a new design rule was proposed based on the direct strength method to predict the web crippling capacities of tested beams. This paper presents the details of this experimental study and the results.
\end{abstract}

Keywords: Cold-formed Steel structures, Unlipped channels, Web crippling, ETF and ITF Load cases, Experiments.

Corresponding author's email address: m.mahendran@qut.edu.au 


\section{Introduction}

Cold-formed steel members are becoming increasingly popular in the building industry due to their superior strength to weight ratio and ease of fabrication as opposed to hot-rolled steel members. Among them DuraGal channel sections are commonly used as bearers of floor systems in residential, industrial and commercial buildings [1]. They are thicker channel sections with varying dimensions to suit various requirements including higher moment capacities and longer spans. Figure 1(a) shows the DuraGal channel section profile while Figure 1(b) shows its applications in buildings as joists and bearers. Table 1 shows the nominal dimensions of DuraGal channel sections available in the market.

Web crippling is one of the failure modes that occurs in steel channel sections at points of transverse concentrated loading or supports applied on a short length of the beam (see Figure 2). Cold-formed steel joists and bearers that are unstiffened against this type of loading are vulnerable to these failures. In a typical floor system, web crippling failures can occur at bearer to column and joist to bearer connections depending on various structural details as given in Table 2. Failure modes of bearers can be different according to the loading locations such as interior columns, end columns and joists supported by bearers. To simulate these practical loading conditions, there are four loading cases for web crippling as recommended in the cold-formed steel specifications including American and Australian standards [2,3]. These loading cases have to be used to investigate the web crippling capacities of coldformed steel beams. They are End-One-Flange (EOF), End-Two-Flange (ETF), Interior-OneFlange (IOF) and Interior-Two-Flange (ITF) loading as shown in Figure 3. One-flange loading or reaction occurs when the clear distance between the bearing edges of adjacent opposite concentrated actions or reactions is greater than $1.5 d_{1}$. Two-flange loading or reaction occurs when the clear distance between the bearing edges of adjacent opposite concentrated actions or reactions is less than or equal to $1.5 d_{1}$. End loading or reaction occurs when the distance from the edge of the bearing to the end of the member is less than or equal to $1.5 d_{1}$. Interior loading or reaction occurs when the distance from the edge of the bearing to the end of the member is greater than $1.5 d_{1}$.

Current cold-formed steel design rules to predict the web crippling capacities are empirical as they were developed based on extensive testing of many cold-formed steel sections such as C-, Z- and hat sections and built-up sections undertaken since 1940s [4-24]. Since 2005, a unified bearing capacity equation has been developed that defines specific coefficients for the 
key parameters influencing the bearing capacities of C-, Z-, Hat and built-up sections [13]. They are clear web height to thickness ratio $\left(d_{1} / t_{w}\right)$, inside bent radius to thickness ratio $\left(r_{i} / t_{w}\right)$ and bearing length to thickness ratio $\left(l_{b} / t_{w}\right)$, in addition to web thickness $\left(t_{w}\right)$ and yield stress $\left(f_{y}\right)[2,3]$. However, it should be noted that these capacity equations are not applicable to some of the DuraGal channels due to the increased inside bent radius to thickness ratios $\left(r_{i} / t_{w}\right)$.

The AISI standard test method published in 2008 [25] presents the details of suitable test procedures that should be adopted in web crippling studies. These test procedures are different to those used by Young and Hancock [19,20] who investigated the web crippling behaviour of unlipped channels with stocky webs using experimental studies. The AISI standard test method [25] recommends that the specimen length should be at least equal to three times the flat portion of clear web height $\left(d_{l}\right)$ for ETF load case while it should be at least equal to five times $d_{1}$ for ITF load case. Web crippling capacities vary with specimen length as this will influence the failure zone. However, test specimen lengths used in the past research [19,20], are different to those recommended by the AISI standard test method [25] for ETF and ITF load cases. Hence there is a need to investigate the effects of using the specimen lengths given in the AISI standard test method on web crippling capacities.

This research is aimed at investigating the web crippling behaviour and strength of unlipped channels with stocky webs under ETF and ITF load cases and determining the accuracy of currently used design rules. Test specimen length and test setup were selected based on the AISI standard test method [25]. Experimental web crippling capacities were compared with the predicted web crippling capacities using the current design rules and suitable modifications were proposed where necessary. New design rules were also developed under the direct strength method format.

\section{Previous Studies on Web Crippling}

The web crippling of cold-formed steel members subjected to different load conditions can be analysed using different theoretical elastic methods [26-28]. However, it should be noted that the web element of a cold-formed steel member is not identical to a four sided simply supported rectangular plate. The web of a cold-formed steel member cannot be considered as a rectangular plate with idealized boundary conditions (simply supported or clamped at its four sides). Also, the determination of critical elastic buckling load does not necessarily imply the failure of the web. Hence the additional load carrying capacity developed in the 
web beyond the elastic buckling load should be estimated. Due to these difficulties associated with the theoretical analysis, most of the previous studies have relied on experimental data in developing web crippling design equations.

Winter and Pian [4] investigated the web crippling capacities of cold-formed steel I-sections under four different load cases while Baehre [7] investigated the web crippling capacities of hat sections subjected to IOF loading. Hetrakul and $\mathrm{Yu}$ [8] researched the web crippling behaviour of cold-formed steel sections having single unreinforced webs. Wing [9] and Wing and Schuster [10] investigated the web crippling capacities of multi-web cold-formed steel sections under all load cases, except for EOF loading case. In this study test specimens were fastened to the reaction supports. Santaputra et al. [11] conducted web crippling tests of hat sections and I-beams fabricated from very high-strength steels under various loading conditions. Bhakta et al. [12] experimentally investigated the influence of the flange restraint on the web crippling capacity of beam web elements.

Prabakaran [13] completed an extensive statistical analysis of the web crippling capacities of cold-formed steel sections by using more than 1200 experimental data found in the literature. The aim of his study was to develop one simplified design equation to calculate the web crippling capacity of cold-formed steel sections. Based on the results of his research, Prabakaran [13] recommended a unified equation with different coefficients for the design of I-sections, single web sections and multi-web sections.

Cain et al. [14] experimentally investigated the web crippling of Z-sections subjected to EOF loading and I-sections subjected to IOF loading. Gerges [15] and Gerges and Schuster [16] investigated the web crippling resistance of single web cold-formed steel members with large inside bent radius to thickness ratios, subjected to EOF loading. Also he developed new parameter coefficients for Prabakaran's [13] web crippling equation based on tests performed on C-sections fastened to the support. An experimental investigation of cold-formed steel stiffened $\mathrm{C}$-and Z-sections subjected to web crippling was carried out by Beshara and Schuster [17]. ETF and ITF loading conditions were considered with particular emphasis on large inside bent radius to thickness ratio $r_{i} / t_{w}$, and the specimens being fastened to the support during testing.

An experimental investigation was carried out by Young and Hancock [20] to investigate the behaviour of cold-formed unlipped channels with stocky webs subjected to web crippling 
under all four loading conditions (EOF, IOF, ETF and ITF). Figure 4 shows the test set-up used by Young and Hancock [20] for ETF load case. Based on the results of their research, the design web crippling strength predictions given by the old American and Australian standards $[29,30]$ were found to be unconservative for the unlipped channel sections tested. In their paper, a simple plastic mechanism expression for web crippling strength of unlipped channels is also proposed.

Recently, Macdonald et al. [21] conducted experimental and numerical studies to investigate the web crippling behaviour of lipped channel beams under ETF, ITF, EOF and IOF load cases. Figure 5 shows the experimental setup used in Macdonald et al.'s [21] tests. They found that the bearing length, corner radius and clear height of web had an effect on the web crippling strength of lipped channel beams (LCB), particularly for the IOF and EOF load cases. Uzzaman et al. [23,24] conducted experimental and numerical studies to investigate the effect of offset web holes on the web crippling strength of cold-formed steel lipped channel beams under ETF and ITF load cases. Figure 6 shows the experimental setup used in Uzzaman et al.'s [23,24] tests. Uzzaman et al. [23,24] also did web crippling tests of LCBs without web openings under the same load cases.

\section{Current Design Rules}

\subsection{AS/NZS 4600 and AISI S100}

In the past, many different design equations have been proposed and used to predict the web crippling capacity of cold-formed steel beams. Web crippling research commenced in 1939 at Cornell University with the first design specification published in 1940 by the American Iron and Steel Institute. Subsequent research at various institutions throughout the world led to the present day design standards in both AS/NZS 4600 [3] and AISI S100 [2]. In the older version of American Specification [29], different design eequations were used to predict the web crippling capacity of cold-formed steel beams. Each of these design equations is only applicable to a certain type of cross section geometry and a particular load case. However, the new unified web crippling capacity equation (Equation 1) adopted in AS/NZS 4600 [3] and AISI S100 [2] is applicable to different types of section geometry and load cases (ETF, ITF, EOF and IOF). These standards provide design guidelines for the bearing capacity $\left(R_{b}\right)$ of open cold-formed steel sections, which is based on Prabakaran [13] who performed an extensive statistical analysis of more than 1200 experimental web crippling capacities of a range of cold-formed steel sections and proposed a suitable unified design equation based on 
four web crippling coefficients (Equation 1). This design rule takes into consideration the clear height of web to thickness ratio $\left(d_{1} / t_{w}\right)$, inside bent radius to thickness ratio $\left(r_{i} / t_{w}\right)$, bearing length to thickness ratio $\left(l_{b} / t_{w}\right)$, yield stress $\left(f_{y}\right)$ and web thickness $\left(t_{w}\right)$. Suitable values of the four coefficients in Equation 1 are given in Table 3 for unlipped channels under ETF and ITF load cases, where the flanges are not connected to the supports (unfastened). It should be noted that these coefficients are applicable for section where the inside bent radius to thickness ratio $\left(r_{i} / t_{w}\right)$ is less than or equal to one.

$R_{b}=C t_{w}^{2} f_{y} \sin \theta\left(1-C_{r} \sqrt{\frac{r_{i}}{t_{w}}}\right)\left(1+C_{l} \sqrt{\frac{l_{b}}{t_{w}}}\right)\left(1-C_{w} \sqrt{\frac{d_{1}}{t_{w}}}\right)$

where $C$ is a coefficient; $t_{w}$ is the web thickness; $r_{i}$ is the inside bent radius; $l_{b}$ is the bearing length; $d_{l}$ is the depth of the flat portion of the web measured along the plane of the web; $f_{y}$ is the yield stress; $\theta$ is the angle between the plane of the web and the plane of the bearing surface and $C_{r}, C_{l}$ and $C_{w}$ are the coefficients of inside bent radius, bearing length and web slenderness, respectively.

\subsection{Young and Hancock [20]}

An experimental study was conducted by Young and Hancock [20] on cold-formed unlipped DuraGal channels with comparatively stocky webs subjected to web crippling. The specimen lengths were taken as bearing length $l_{b}$ plus $1.5 d$ and $3 d$ for ETF and ITF load cases, respectively, where $d$ is the overall depth of the section. Test results were compared with the design equations in the older version of AS/NZS 4600 [30] and AISI [29]. It was found that these design equations are unconservative for unlipped channels. Tables 4 and 5 show the web crippling capacities of DuraGal channels from their tests, which are compared with the predictions from the current design equations based on AS/NZS 4600 [3] and AISI S100 [2]. The design rules in AS/NZS 4600 are identical to those in AISI S100, and hence only AS/NZS 4600 values are reported in this paper. The mean values of test to predicted web crippling capacities of unlipped channels by AS/NZ 4600 [3] are 0.95 and 1.05 for ETF and ITF load cases, respectively. The corresponding coefficients of variation (COV) are 0.12 and 0.16, respectively. Tables 4 and 5 results show that AS/NZS 4600 [3] and AISI S100 [2] design equations are up to $25 \%$ unconservative for some of the channel sections when higher bearing lengths are used. Also, these design equations are not applicable to sections with larger $r_{i} / t_{w}$ ratios. Hence there is a need to investigate the applicability of the current AS/NZS 4600 and AISI S100 design equations for larger bearing lengths. 
Based on their test results, Young and Hancock [20] developed design equations to predict the web crippling capacities of channels with stocky webs. These equations were derived using a combination of theoretical and empirical analyses. It was assumed that the bearing load is applied eccentrically to the web due to the presence of corner radii, which produces bending of the web out of its plane. This will cause a plastic mechanism as shown in Figures 7 and 8 where $N_{m}$ is the assumed mechanism length.

$$
\begin{gathered}
P_{p m}=\frac{M_{p} N_{m}}{r}\left[C_{a}-C_{b}\left(\frac{h}{t_{w}}\right)\right] \\
\text { with } \quad M_{p}=\frac{f_{y} t_{w}{ }^{2}}{4} \\
r=r_{i}+\frac{t_{w}}{2} \\
N_{m}=N+i d \text { for interior loading } \\
N_{m}=N+\frac{e d}{2} \text { for end loading }
\end{gathered}
$$

where $P_{p m}$ is the web crippling strength; $M_{p}$ is the plastic moment per unit length; $r$ and $r_{i}$ are the centerline and inside corner radii, respectively; $h$ is the depth of the flat portion of the web; $d$ is the overall depth of the web; $t_{w}$ is the web thickness; $f_{y}$ is the yield stress; and $N$ is the bearing length; $C_{a}=1.44$ and $C_{b}=0.0133$. The correction factors for interior loading are $i=$ 1.3 and 1.4 for IOF and ITF load cases, respectively, and the correction factors for end loading are $e=1.0$ and 0.6 for EOF and ETF load cases, respectively.

The bearing failure for a smaller bearing length is likely to be flange crushing (failure at the corner region instead of web crippling (failure at the web mid-height). These two different failure modes were not considered separately in Young and Hancock [20] who compared all their test results with their proposed equation as shown in Tables 4 and 5. It was observed that some of the test/predicted ratios were much higher than one, indicating possible flange crushing. However, it should be noted that Young and Hancock's [20] design equation is only suitable for channels subjected to web crippling (plastic mechanism at the middle of the web) 
and hence their empirical co-efficients should be modified by considering only the test results for pure web crippling failures.

\section{Experimental Study}

Following a review of the previous studies on web crippling of unlipped channel beams, two series of experimental studies were conducted to investigate the behaviour of cold-formed steel unlipped channels with stocky webs subject to web crippling under ETF and ITF load cases. Forty two tests were conducted with flanges of test sections not fastened to the bearing plates.

\subsection{Test Specimens}

Suitable test sections and thicknesses were selected based on the available literature and the standard DuraGal sections and thicknesses commonly used in structural applications. The section depth of DuraGal steel channels varies from $75 \mathrm{~mm}$ to $300 \mathrm{~mm}$ while their thickness varies from $4 \mathrm{~mm}$ to $8 \mathrm{~mm}$. Hence seven commonly used sections with three nominal thicknesses of 4, 5 and $6 \mathrm{~mm}$ were selected in the current study. Tables 6 and 7 include their measured external dimensions ( $d$ and $\left.b_{f}\right)$, thicknesses $\left(t_{w}\right)$, internal corner radius $\left(r_{i}\right)$ and length $(L)$. Four bearing lengths $l_{b}(25,50 \mathrm{~mm}, 100 \mathrm{~mm}$ and $150 \mathrm{~mm})$ were used for both ETF and ITF load cases. Test specimen length and test setup were selected based on the AISI standard test method [25]. Accordingly the specimen length should be at least equal to three times the flat portion of clear web height $\left(d_{1}\right)$ for the ETF load case while it should be at least equal to five times the flat portion of clear web height for the ITF load case.

The nominal yield stress of DuraGal steel channel sections considered in this study is 450 MPa. However, an experimental study was undertaken to determine the accurate mechanical properties. Tensile coupon tests were conducted on seven different sections to obtain their stress-strain curves and mechanical properties (elastic modulus, yield stress and ultimate strength). Test specimens were cut in the longitudinal direction of DuraGal steel sections. Their shapes and sizes were in accordance with AS 1391 [31]. The base metal thickness and width of each specimen were measured at three points within the gauge length using a micrometer and a vernier calliper, respectively. The averages of these measured dimensions were used in the calculations of mechanical properties. The tensile specimens were tested in a $50 \mathrm{kN}$ Instron testing machine by loading at a constant strain rate $\left(3.3 \times 10^{-4} \mathrm{~s}^{-1}\right)$ until failure. 
Table 8 summarizes the mechanical properties (yield stress, ultimate stress and elastic modulus) determined from the tensile coupon tests.

\subsection{Test Set-up and Procedure}

Figures 9 and 10 show the test set-up used in the web crippling tests of this research for ETF and ITF load cases, respectively (see Figures 3(c) and (d)). Tests were conducted using a 300 $\mathrm{kN}$ Instron testing machine in the Structural Laboratory at the Queensland University of Technology. The support system was designed to ensure that the test beam had pinned supports at the top and bottom using half rounds. Single channel section was considered for ETF and ITF load cases as was done in [20-24]. It should be noted that no sign of twisting was observed during experiments.

Test specimens were located between the bearing plates and a small load was applied first to allow the loading and support systems to settle evenly on the bearings. The measuring system was then initialised with zero values and the loading was commenced. The cross-head of the testing machine was moved at a constant rate of $0.7 \mathrm{~mm} /$ minute until failure. During the tests, the displacements were recorded in addition to the applied load. Two laser displacement transducers were located on the test beam near the loading point to measure the vertical (flange) and lateral (web) deflections, respectively, as shown in Figures 9 and 10.

\subsection{Test Results and Discussion}

Tables 6 and 7 show the web crippling capacities (ultimate loads) of DuraGal channel sections as obtained from this experimental study for ETF and ITF load cases, respectively while Figures 11 and 12 show the typical failure modes of channels under these load cases, respectively. It was observed that the influence zone length extended to more than the specimen length used by Young and Hancock [20] for some of the test specimens. This behaviour varied between the tests depending on the web crippling parameters $\left(r_{i} / t_{w}, l_{b} / t_{w}\right.$ and $d_{1} / t_{w}$ ratios). Tests I1-I5 and E1-E5 were undertaken to study the effect of specimen length and their results show that the ultimate load increased by $5-10 \%$ when the specimen length was increased to the values recommended by the AISI test method [25]. This variation is expected to increase further with increased $r_{i} / t_{w}, l_{b} / t_{w}$ and $d_{1} / t_{w}$ ratios. Hence it is concluded that the lengths proposed by the AISI testing method in [25] should be used for web crippling tests under ETF and ITF load cases. Further finite element analysis based research is 
continuing to investigate the web crippling behaviour of channel sections with varying lengths under ETF and ITF load cases.

Two of the tests were repeated and the consistency of test results was validated (see Table 6). Young and Hancock's [20] tests were based on shorter lengths and these tests (Tables 4 and 5) were repeated in our study (with shorter lengths) and their results reasonably agree with our corresponding results in Tables 6 and 7. Their test results were found to be only slightly higher for the same length. This may be due to the varying imperfection levels and possible variations in the yield strength of the test specimens. It was also observed that web crippling capacities did not vary much for Section $100 \times 50 \times 4$ with different lengths, considering the experimental variations such as cross-sectional dimensions and imperfections.

Tables 9 and 10 compare the test results with the predictions from the current and proposed design rules. Only the test samples which comply with the AISI standard test method [25] are considered in these tables. Figure 13 shows the failure mode of combined flange crushing and web crippling of channel sections when smaller bearing lengths were used. Such combined flange crushing and web crippling failures were not considered here for further investigations in Tables 9 and 10. Figures 14(a) and (b) show the typical load versus deflection curves from the web crippling tests under ETF and ITF load cases, respectively. Figure 15 shows the typical load versus deflection curves for a DuraGal section (Test E-2) with flange bent outwards (Stage 1 in Figure 15). In this case the load versus deflection curves were nearly flat in the initial stage of the test. The section withstood about 1-2 $\mathrm{kN}$ until the flanges were bent to the horizontal position by the loading plate (Stage 2). Thereafter the section deformed (similar to other tests) as shown in Figure 15 (Stage 3) and failed by forming a hinge at web mid height (Stage 4).

Experimental ultimate web crippling capacities are compared with the predictions from the design equation (Equation 1) based on AS/NZS 4600 [3] and AISI S100 [2] in Tables 9 and 10. For the prediction of web crippling capacities, support and flange conditions were taken as unfastened, unstiffened flanges and two-flange loading or reaction based on Table 2 and the corresponding web crippling coefficients are given in Table 11. It should be noted that, when applying the design rules of AS/NZS 4600, the coefficients prescribed by the standards are used. For ETF load case, the mean value of test to predicted web crippling capacity of unlipped channels with stocky webs by AS/NZS 4600 is 0.85 while the corresponding 
coefficient of variation (COV) is 0.07 . For ITF load case, the mean value of test to predicted web crippling capacity by AS/NZS 4600 is 0.86 while the corresponding COV is 0.08 . Tables 9 and 10 show that AS/NZS 4600 and AISI S100 design equations are about 26\% unconservative for some cases under ETF load case while they are 22\% unconservative under ITF load case.

Experimental ultimate web crippling capacities are also compared with the predictions from the design equation given in Young and Hancock [20] (Tables 9 and 10). The web crippling coefficients proposed by Young and Hancock are given in Table 12. For ETF load case, the mean value of test to predicted web crippling capacity of unlipped channels with stocky webs by Young and Hancock [20] is 0.82 while the corresponding coefficient of variation (COV) is 0.22 . For ITF load case, the mean value of test to predicted web crippling capacity is 0.88 while the corresponding COV is 0.15 . Tables 9 and 10 show that Young and Hancock's [20] design equations are up to $47 \%$ unconservative under ETF load case and they are up to $31 \%$ unconservative under ITF load case, when higher bearing lengths are used.

Based on the comparison of test results with the currently available design rules, it was found that they are not accurately predicting the web crippling capacities of stocky web channels. Hence there is a need to modify the existing design rules and/or propose new design rules to predict the web crippling capacities of unlipped channels with stocky webs.

\section{Proposed Design Rules}

\subsection{AS/NZS 4600 and AISI S100}

Since the currently available web crippling capacity equations were found to be unconservative for unlipped channels with stocky webs, new design equations are proposed to predict the web crippling capacities of these channels based on experimental results. This approach is similar to that used in the current cold-formed steel design codes $[2,3]$ in which Equation 1 is proposed with modified web crippling coefficients $C, C_{r}, C_{l}$ and $C_{w}$ given in Table 11. Experimental ultimate web crippling capacities are compared with the predictions from Equation 1 with the proposed coefficients (Proposal 1(a)). For ETF load case, the mean value of test to predicted web crippling capacity of unlipped channels with stocky webs is 1.00 while the corresponding $\mathrm{COV}$ is 0.05 . For ITF load case, the mean value of test to predicted web crippling capacity is 1.01 while the corresponding COV is 0.04 . It shows that the web crippling capacities predicted by Equation 1 with proposed coefficients agree well 
with the experimental web crippling capacities of unlipped channels with stocky webs under ETF and ITF load cases.

\section{Capacity Reduction Factor $\left(\phi_{w}\right)$}

The North American Cold-formed Steel Specification [2] recommends a statistical model to determine the capacity reduction factor. This model accounts for the variations in material, fabrication and loading effects. The capacity reduction factor is given by Equation 6 .

$$
\phi_{w}=1.52 M_{m} F_{m} P_{m} e^{-\beta_{0} \sqrt{\left\{V_{m}^{2}+V_{f}^{2}+C_{p} V_{p}^{2}+V_{q}^{2}\right\}}}
$$

where $\phi_{\mathrm{w}}$ is capacity reduction factor; $\mathrm{M}_{\mathrm{m}}, \mathrm{V}_{\mathrm{m}}$ are mean and coefficient of variation of the material factor $=1.1,0.1 ; \mathrm{F}_{\mathrm{m}}$ and $\mathrm{V}_{\mathrm{f}}$ are mean and coefficient of variation of the fabrication factor $=1.0,0.05 ; \mathrm{V}_{\mathrm{q}}$ is coefficient of variation of load effect $=0.21 ; \beta_{0}$ is target reliability index for cold-formed steel members $=2.5 ; \mathrm{C}_{\mathrm{p}}$ is correction factor depending on the number

of tests $=\left[1+\frac{1}{n}\right]\left[\frac{m}{m-2}\right] ; \mathrm{P}_{\mathrm{m}}$ is mean value of the tested to predicted load ratio; $\mathrm{V}_{\mathrm{p}}$ is coefficient of variation of the tested to predicted load ratio, but not less than $6.5 \% ; \mathrm{n}$ is number of tests, $\mathrm{m}$ is degree of freedom $=\mathrm{n}-1$.

Using Equation 6 with the mean and COV values in Table 11 gave capacity reduction factors $\left(\phi_{\mathrm{w}}\right)$ of 0.91 and 0.92 for ETF and ITF load cases, respectively for Proposal 1(a). The coefficient $C$ was modified in Proposal 1(b) (Table 11) in order to propose a universal capacity reduction factor of 0.85 for web crippling subjected to ETF and ITF load cases.

\subsection{Young and Hancock [20]}

It was found that the web crippling design equations proposed by Young and Hancock [20] are unsafe for some DuraGal channels. Hence new coefficients are proposed in Table 12 to predict their web crippling capacities using Equation 2 (Proposal 2). Experimental ultimate web crippling capacities are compared with the predictions in Tables 9 and 10 using the proposed coefficients given in Table 12. For ETF load case, the mean value of test to predicted web crippling capacity of DuraGal channel is 1.01 while the corresponding COV is 0.09 . For ITF load case, the mean value of test to predicted web crippling capacity is 1.00 while the corresponding COV is 0.10 . It shows that the web crippling capacities predicted by Equation 2 with the proposed coefficients in Table 12 agree well with the experimental web crippling capacities of unlipped channels with stocky webs under ETF and ITF load cases. 
The corresponding capacity reduction factors $\left(\phi_{\mathrm{w}}\right)$ are 0.88 and 0.86 for ETF and ITF load cases, respectively.

\subsection{Direct Strength Method (DSM)}

The DSM proposed by Schafer [32] is one of the alternative methods to determine the strength of cold-formed steel members. Recently Keerthan and Mahendran [33] have developed suitable DSM based equations for web crippling of a hollow flange channel beam. A similar approach was used to develop suitable design rules for the web crippling capacity of unlipped channel sections under the DSM format (Proposal 3). Equations 7(a) and (b) show the proposed DSM design equations for the web crippling capacity of unlipped channel sections under ETF and ITF load cases, respectively. In these equations the DSM based nominal web crippling capacity $\left(P_{u}\right)$ is proposed using $P_{c r}$ (elastic buckling capacity in web crippling) and $P_{y}$ (web yield capacity).

Equations 8(a) and (b) present the equivalent yield capacities in web crippling based on a $45^{\circ}$ load distribution to the middle from the bearing plate edges for ETF and ITF load cases, respectively. The effect of corners on the yield capacity was not considered in Equations 8(a) and (b). Detailed finite element analyses will be carried out to investigate the effect of corners on the yield capacity in web crippling $\left(P_{y}\right)$.

The buckling loads $\left(P_{c r}\right)$ can be calculated using Equation 9, provided a realistic buckling coefficient $(k)$ is known. Lagerqvist and Johansson [34] proposed a suitable equation for the buckling coefficient of plate girders under ITF load case. Based on preliminary numerical studies the buckling coefficients for the ETF and ITF load cases were found to be approximately 1 and 2, respectively. Detailed finite element analyses will be carried out to recalibrate Lagerqvist and Johansson's [34] equation to suit unlipped channels with stocky webs under ETF and ITF load cases.

$$
\begin{array}{ll}
\frac{P_{u}}{P_{y}}=0.187\left[1-0.04\left(\frac{P_{c r}}{P_{y}}\right)^{0.5}\right]\left(\frac{P_{c r}}{P_{y}}\right)^{0.5} & \text { for ETF load case } \\
\frac{P_{u}}{P_{y}}=0.283\left[1-0.04\left(\frac{P_{c r}}{P_{y}}\right)^{0.5}\right]\left(\frac{P_{c r}}{P_{y}}\right)^{0.5} & \text { for ITF load case }
\end{array}
$$


$P_{y}=f_{y w} t_{w}\left(l_{b}+\frac{d_{1}}{2}\right)$

$P_{y}=f_{y w} t_{w}\left(l_{b}+d_{1}\right)$

$P_{c r}=\frac{\pi^{2} E k t_{w}^{3}}{12\left[1-v^{2}\right] d}$

$\lambda=\sqrt{\frac{P_{y}}{P_{c r}}}$

for ETF load case

for ITF load case

Experimental ultimate web crippling capacity results were processed within the DSM format and are shown in Figures 16(a) and (b) for ETF and ITF load cases, respectively, where the slenderness $(\lambda)$ was calculated using Equation 10. These figures show the non-dimensional web crippling capacity curves for unlipped channel sections and compare them with experimental results. It can be seen that the proposed DSM equations predict the web crippling capacities of unlipped channel sections reasonably well (Tables 9 and 10). Further FEA based research is continuing to improve the buckling coefficients $(k)$ and DSM equations using more web crippling capacity data.

\subsection{Simplified Method for DuraGal Channels}

The Duragal channels are comparatively stocky among the commonly used cold-formed steel members since their thicknesses vary from 4 to $8 \mathrm{~mm}$. It was found that these sections failed inelastically in our experimental study. Figures 17(a) and (b) show that the variation of $P_{\text {Test }} /\left(P_{c r} P_{y}\right)^{0.5}$ ratios with respect to slenderness $\left(\lambda=\left(P_{y} / P_{c r}\right)^{0.5}\right)$ is a constant for ETF and ITF load cases, respectively. Using this outcome it was decided to propose a simplified method (Equation 11) as was done in $[35,36]$ for the shear capacity of steel beams. Tables 9 and 10 show that the web crippling capacities predicted by Equation 11 (Proposal 4) agree well with the experimental results of DuraGal channels under ETF and ITF load cases, respectively. Hence Equation 11 can be used to predict the web crippling capacities of (DuraGal) channels with stocky webs under these load conditions.

$P_{u}=n\left(P_{c r} P_{y}\right)^{0.5} \quad$ for ETF and ITF load cases

where $P_{c r}$ and $P_{y}$ are obtained from Equations 8 and $9 ; n=0.18$ and 0.28 for ETF and ITF load cases, respectively. 


\section{Conclusions}

This paper has described an experimental investigation into the web crippling capacities of cold-formed steel unlipped channels with stocky webs under ETF and ITF load cases. Forty two tests were conducted on DuraGal channel sections with stocky webs under different bearing lengths. The flanges of these channel sections were not fastened to the supports in this study. A full description of the web crippling behaviour of cold-formed steel sections is presented in this paper including ultimate loads, failure modes and load-deformation curves. It was found that the specimen lengths proposed by the AISI testing method should be used for web crippling tests under ETF and ITF load cases. A detailed comparison of ultimate web crippling capacity results with those predicted by the current design equations in AS/NZS 4600, AISI S100 and Young and Hancock [20] showed that these equations are unconservative for these stocky channel sections under ETF and ITF load cases. Hence new design equations were proposed within these guidelines to accurately predict the web crippling capacities of unlipped channel sections based on test results. Suitable design rules for the web crippling capacities of unlipped channel sections were also developed under the direct strength method format. Further finite element analyses are continuing to improve the DSM equations using more web crippling capacity data.

\section{Acknowledgment}

The authors would like to thank Australian Research Council and Austube Mills for their financial support, and the Queensland University of Technology for providing the necessary facilities and support to conduct this research project. They would also like to thank Mr. Francis Ho and Mr Yixiang Lu for their valuable assistance in performing the web crippling tests.

\section{References}

[1] Austube Mills, Available from <http://www.austubemills.com.au/product/channels $>$, [22 July 2014].

[2] American Iron and Steel Institute (AISI) (2007), Specifications for the cold-formed steel structural members, Cold-formed Steel Design Manual, AISI S100, Washington, USA.

[3] Standards Australia (SA) (2005), Cold-formed steel structures, AS/NZS 4600, Sydney, Australia. 
[4] Winter, G. and Pian, R.H.J. (1946), Crushing strength of thin steel webs, Engineering Experiment, Bulletinno.35, Cornell University, New York, USA.

[5] Khan, M. Z. and Walker, A.C. (1972), Buckling of plates subjected to localized edge loading, Structural Engineer, Vol. 50, pp.225-232.

[6] Walker, A.C. (1975), Design and analysis of cold-formed sections, John Wiley and Sons, New York, U.S.A.

[7] Baehre, R. (1975), Sheet metal panels for use in building construction - Recent research projects in Sweden, Proceeding of the Third International Specialty Conference on Coldformed Steel Structures, University of Missouri-Rolla, Rolla, Missouri, U.S.A.

[8] Hetrakul, N., and Yu, W.W. (1978), Structural behaviour of beam webs subjected to web crippling and a combination of web crippling and bending, Final Report, Civil Engineering Study 78-4, University of Missouri-Rolla, Rolla, Missouri, U.S.A.

[9] Wing, B.A. (1981), Web Crippling and the interaction of bending and web crippling of unreinforced multi-web cold-formed steel sections, M.A.Sc. Thesis, University of Waterloo, Waterloo, ON, Canada.

[10] Wing, B.A. and Schuster, R.M. (1982), Web crippling for decks subjected to two-flange loading, Proceedings of the Sixth International Specialty Conference on Cold-formed Steel Structures, University of Missouri-Rolla, Rolla, MO, U.S.A.

[11] Santaputra, C. (1986), Web crippling of high strength cold formed steel beams, Ph.D. Thesis, University of Missouri-Rolla, Rolla, Missouri, U.S.A.

[12] Bhakta, B.H., LaBoube, R.A., and Yu, W.W. (1992), The effect of flange restraint on web crippling strength, Final Report, Civil Engineering Study 92-1, University of MissouriRolla, Rolla, Missouri, U.S.A. 
[13] Prabakaran, K. (1993), Web crippling of cold-formed steel sections, Project Report, Department of Civil Engineering, University of Waterloo, Waterloo, Ontario, Canada.

[14] Cain, D.E., LaBoube, R.A. and Yu, W.W. (1995), The effect of flange restraint on web crippling strength of cold formed steel Z-and I-sections, Final Report, Civil Engineering Study 95-2, University of Missouri-Rolla, Rolla, Missouri, U.S.A.

[15] Gerges, R.R. (1997), Web crippling of single web cold formed steel members subjected to end one-flange loading, M.A.Sc. Thesis, University of Waterloo, Waterloo, Ontario, Canada.

[16] Gerges, R.R., and Schuster, R.M. (1998), Web crippling of single web cold formed steel members subjected to end one-flange loading, Fourth International Specialty Conference on Cold-formed Steel Structures, St. Louis, Missouri, U.S.A.

[17] Beshara, B. and Schuster, R.M. (2000), Web crippling data and calibrations of coldformed steel members, Final Report, University of Waterloo, Waterloo, Canada.

[18] Rhodes, J. and Nash, D. (1998), An investigation of web crushing behaviour in thinwalled beams, Thin-Walled Structures, Vol. 32, pp. 207-230.

[19] Young, B. and Hancock, G.J. (1998), Web crippling behaviour of cold-formed unlipped channels, Proceeding of the $14^{\text {th }}$ International Specialty Conference on Cold-formed Steel Design and Construction, Missouri, USA, pp. 127-150.

[20] Young, B., and Hancock, G.J. (2001), Design of cold-formed channels subjected to web crippling, Journal of Structural Engineering, Vol. 127, pp.1137-1144.

[21] Macdonald, M., Heiyantuduwa, M.A., Kotelko, M. and Rhodes, J. (2011), Web crippling behaviour of thin-walled lipped channel beams, Thin-Walled Structures, Vol. 49, pp. 682690. 
[22] Macdonald, M. and Heiyantuduwa, M.A. (2012), A design rule for web crippling of cold-formed steel lipped channel beams based on nonlinear FEA, Thin-Walled Structures, Vol. 53, pp. 123-130.

[23] Uzzaman, A., Lim, J.B.P., Nash, D., Rhodes, J. and Young, B. (2013), Effect of offset web holes on web crippling strength of cold-formed steel channel sections under End-TwoFlange loading condition, Thin-Walled Structures Vol.65, pp.34-48.

[24] Uzzaman, A., Lim, J.B.P., Nash, D., Rhodes, J. and Young, B. (2013), Web crippling behaviour of cold-formed steel channel sections with offset web holes subjected to InteriorTwo-Flange loading, Thin-Walled Structures, Vol.50, pp.76-86.

[25] American Iron and Steel Institute (AISI) (2008), Standard test method for determining the web crippling strength of cold-formed steel beams, TS-9-05, DC, USA.

[26] Timoshenko, S.P. and Gere, G.M. (1961), Theory of elastic stability, Second Edition, McGraw-Hill, New York, U.S.A.

[27] Walker, A.C. (1975), Design and analysis of cold formed sections, Jhon Wiley \& Sons, New York, U.S.A.

[28] Zetlin, L. (1955), Elastic instability of flat plates subjected to partial edge loads, Journal of the Structural Division, ASCE Proceedings, Vol. 81.

[29] American Iron and Steel Institute (AISI) (1996), Specification for the design of coldformed steel structural members, Washington, D.C, U.S.A.

[30] Standards Association of Australia (SAA) (1996), Cold-formed steel structures, AS/NZS 4600, Sydney, Australia.

[31] Standards Australia (SA) (2007), Methods for tensile testing of metal, AS 1391, Sydney, Australia. 
[32] Schafer, B.W. (2008), Review: The direct strength method of cold-formed steel member design, Journal of Constructional Steel Research, Vol. 64, pp. 766-778

[33] Keerthan, P. and Mahendran, M. (2014), Experimental study of web crippling behaviour of hollow flange channel beams under two flange load cases. Thin-Walled Structures, In press.

[34] Lagerqvist, O. and Johansson, B. (1996), Resistance of I girders to concentrated loads, Journal of Constructional Steel Research, Vol. 39, pp. 87-119.

[35] Hancock, G. J. (2007), Design of cold-formed steel structures, $4^{\text {th }}$ Edition, Australian Steel Institute, Australia.

[36] Keerthan, P. and Mahendran, M. (2011), Numerical modelling of LiteSteel beams subject to shear, Journal of Structural Engineering, Vol. 137, pp. 1428-1439. 
Table Captions

Table 1: Duragal channel sections

Table 2: Different conditions for single web channel sections

Table 3: AS/NZS 4600 web crippling coefficients for unfastened unlipped channels under ETF and ITF load cases

Table 4: Young and Hancock's [20] test results for ETF load case Table 5: Young and Hancock's [20] test results for ITF load case

Table 6: Test specimen details and results for ETF load case

Table 7: Test specimen details and results for ITF load case

Table 8: Mechanical properties of steel used in test specimens

Table 9: Comparison of test results with predictions for ETF load case

Table 10: Comparison of test results with predictions for ITF load case

Table 11: Proposed coefficients based on AS/NZS 4600 design rules

Table 12: Proposed coefficients based on Young and Hancock's [20] design rules 
Table 1: Duragal channel sections

\begin{tabular}{|c|c|c|c|c|}
\hline Section & $\begin{array}{l}\text { Depth } \\
\mathrm{d}(\mathrm{mm})\end{array}$ & $\begin{array}{l}\text { Flange } \\
\mathrm{b}_{\mathrm{f}}(\mathrm{mm})\end{array}$ & $\begin{array}{c}\text { Thickness } \\
\mathrm{t}_{\mathrm{w}}(\mathrm{mm})\end{array}$ & $\begin{array}{l}\text { Radius } \\
\mathrm{r}_{\mathrm{i}}(\mathrm{mm})\end{array}$ \\
\hline $300 \times 90 \times 8$ & 300 & 90 & 8.0 & 8 \\
\hline $300 \times 90 \times 6$ & 300 & 90 & 6.0 & 8 \\
\hline $250 \times 90 \times 6$ & 250 & 90 & 6.0 & 8 \\
\hline $230 \times 75 \times 6$ & 230 & 75 & 6.0 & 8 \\
\hline $200 \times 75 \times 6$ & 200 & 75 & 6.0 & 8 \\
\hline $200 \times 75 \times 5$ & 200 & 75 & 4.7 & 4 \\
\hline $180 \times 75 \times 5$ & 180 & 75 & 4.7 & 4 \\
\hline $150 \times 75 \times 5$ & 150 & 75 & 4.7 & 4 \\
\hline $125 \times 65 \times 4$ & 125 & 65 & 3.8 & 4 \\
\hline $100 \times 50 \times 4$ & 100 & 50 & 3.8 & 4 \\
\hline $75 \times 40 \times 4$ & 75 & 40 & 3.8 & 4 \\
\hline
\end{tabular}


Table 2: Different conditions for single web channel sections

\begin{tabular}{|c|c|c|}
\hline Conditions & \multicolumn{2}{|c|}{ Options } \\
\hline Support condition & \multicolumn{2}{|c|}{ Fastened versus Unfastened } \\
\hline Flange condition & \multicolumn{2}{|c|}{$\begin{array}{l}\text { Stiffened versus Unstiffened } \\
\text { (Lipped versus Un-lipped) }\end{array}$} \\
\hline Loading condition & One flange versus Two flanges & \multirow{2}{*}{$\begin{array}{l}\text { EOF, IOF, ETF and ITF load } \\
\text { cases }\end{array}$} \\
\hline Loading location & End versus Interior & \\
\hline
\end{tabular}

Table 3: AS/NZS 4600 web crippling coefficients for unfastened unlipped channels under ETF and ITF load cases

\begin{tabular}{|c|c|c|c|c|c|c|c|c|c|}
\hline Load case & $\mathrm{C}$ & $\mathrm{C}_{\mathrm{r}}$ & $\mathrm{C}_{\mathrm{l}}$ & $\mathrm{C}_{\mathrm{w}}$ & $\phi_{\mathrm{w}}$ & $\mathrm{r}_{\mathrm{i}} / \mathrm{t}_{\mathrm{w}}$ & $\mathrm{d}_{1} / \mathrm{t}_{\mathrm{w}}$ & $\mathrm{l}_{\mathrm{b}} / \mathrm{t}_{\mathrm{w}}$ & $\mathrm{1}_{\mathrm{b}} / \mathrm{d}_{1}$ \\
\hline ETF & 2 & 0.11 & 0.37 & 0.01 & 0.75 & $\leq 1$ & \multirow{2}{*}{$\leq 200$} & $\leq 210$ & $\leq 2$ \\
\hline ITF & 13 & 0.47 & 0.25 & 0.04 & 0.80 & $\leq 1$ & & & $\leq$ \\
\hline
\end{tabular}

$\phi_{\mathrm{w}}=$ Capacity reduction factor 
Table 4: Young and Hancock's [20] test results for ETF load case

\begin{tabular}{|c|c|c|c|c|c|c|c|c|c|c|}
\hline \multirow[b]{2}{*}{ Section } & \multirow[b]{2}{*}{$\begin{array}{c}\mathrm{d} \\
(\mathrm{mm})\end{array}$} & \multirow[b]{2}{*}{$\begin{array}{c}\mathrm{b}_{\mathrm{f}} \\
(\mathrm{mm})\end{array}$} & \multirow[b]{2}{*}{$\begin{array}{c}\mathrm{t}_{\mathrm{w}} \\
(\mathrm{mm})\end{array}$} & \multirow[b]{2}{*}{$\begin{array}{c}\mathrm{r}_{\mathrm{i}} \\
(\mathrm{mm})\end{array}$} & \multirow[b]{2}{*}{$\begin{array}{c}\mathrm{L} \\
(\mathrm{mm})\end{array}$} & \multirow[b]{2}{*}{$\begin{array}{c}\mathrm{l}_{\mathrm{b}} \\
(\mathrm{mm})\end{array}$} & \multirow[b]{2}{*}{$\begin{array}{c}\mathrm{f}_{\mathrm{y}} \\
(\mathrm{MPa})\end{array}$} & \multirow[b]{2}{*}{$\begin{array}{c}\text { Test } \\
\text { Ultimate } \\
\text { load }(\mathrm{kN})\end{array}$} & \multicolumn{2}{|c|}{ Ultimate load ratios } \\
\hline & & & & & & & & & $\begin{array}{c}\text { Test/ } \\
\text { AS/NZS } \\
4600\end{array}$ & $\begin{array}{l}\text { Test/ } \\
\text { Eq. (2) }\end{array}$ \\
\hline \multirow{2}{*}{$300 \times 90 \times 6$} & 298.3 & 91.2 & 6.01 & 8.4 & 495.2 & 45 & 435 & 45.4 & 0.88 & 1.16 \\
\hline & 298.5 & 90.9 & 5.98 & 8.4 & 539.6 & 90 & 435 & 49.4 & 0.80 & 0.96 \\
\hline \multirow{2}{*}{$250 \times 90 \times 6$} & 249.4 & 89.9 & 5.98 & 7.9 & 421 & 45 & 445 & 46.9 & 0.89 & 1.13 \\
\hline & 249.2 & 89.8 & 5.98 & 7.9 & 465.1 & 90 & 445 & 50.6 & 0.80 & 0.89 \\
\hline \multirow{2}{*}{$200 \times 75 \times 5$} & 198.7 & 75.9 & 4.72 & 4.2 & 336.9 & 37.5 & 415 & 31.2 & 0.98 & 0.98 \\
\hline & 198.9 & 75.9 & 4.72 & 4.2 & 375.3 & 75 & 415 & 40.2 & 1.04 & 0.91 \\
\hline \multirow{2}{*}{$125 \times 65 \times 4$} & 125.3 & 65.3 & 3.84 & 3.9 & 219.8 & 32.5 & 405 & 23.4 & 1.12 & 1.23 \\
\hline & 125.6 & 65.4 & 3.83 & 3.9 & 252.5 & 65 & 405 & 28.2 & 1.12 & 1.02 \\
\hline \multirow{2}{*}{$100 \times 50 \times 4$} & 99.4 & 50.3 & 3.83 & 4.1 & 175 & 25 & 440 & 22.6 & 1.07 & 1.34 \\
\hline & 99.1 & 50.4 & 3.83 & 4.1 & 200.2 & 50 & 440 & 24.8 & 0.97 & 1.01 \\
\hline \multirow{2}{*}{$75 \times 40 \times 4$} & 74.4 & 40.4 & 3.84 & 3.9 & 113.6 & 20 & 450 & 18.3 & 0.88 & 1.23 \\
\hline & 74.3 & 40.5 & 3.85 & 3.9 & 152 & 40 & 450 & 22.1 & 0.88 & 1.00 \\
\hline \multicolumn{9}{|c|}{ Mean } & 0.95 & 1.07 \\
\hline \multicolumn{9}{|c|}{$\mathrm{COV}$} & 0.12 & 0.13 \\
\hline
\end{tabular}

Elastic modulus $=203,000 \mathrm{MPa}$ 
Table 5: Young and Hancock's [20] test results for ITF load case

\begin{tabular}{|c|c|c|c|c|c|c|c|c|c|c|}
\hline \multirow[b]{2}{*}{ Section } & \multirow[b]{2}{*}{$\begin{array}{c}\mathrm{d} \\
(\mathrm{mm})\end{array}$} & \multirow[b]{2}{*}{$\begin{array}{c}\mathrm{b}_{\mathrm{f}} \\
(\mathrm{mm})\end{array}$} & \multirow[b]{2}{*}{$\begin{array}{c}\mathrm{t}_{\mathrm{w}} \\
(\mathrm{mm})\end{array}$} & \multirow[b]{2}{*}{$\begin{array}{c}\mathrm{r}_{\mathrm{i}} \\
(\mathrm{mm})\end{array}$} & \multirow[b]{2}{*}{$\begin{array}{c}\mathrm{L} \\
(\mathrm{mm})\end{array}$} & \multirow[b]{2}{*}{$\begin{array}{c}\mathrm{l}_{\mathrm{b}} \\
(\mathrm{mm})\end{array}$} & \multirow[b]{2}{*}{$\begin{array}{c}\mathrm{f}_{\mathrm{y}} \\
(\mathrm{MPa})\end{array}$} & \multirow[b]{2}{*}{$\begin{array}{c}\text { Test } \\
\text { ultimate } \\
\text { load }(\mathrm{kN})\end{array}$} & \multicolumn{2}{|c|}{ Ultimate load ratios } \\
\hline & & & & & & & & & $\begin{array}{c}\text { Test/ } \\
\text { AS/NZS } \\
4600\end{array}$ & $\begin{array}{l}\text { Test/ } \\
\text { Eq. (2) }\end{array}$ \\
\hline \multirow{2}{*}{$300 \times 90 \times 6$} & 298.6 & 91 & 5.97 & 8.4 & 944.1 & 45 & 435 & 144.6 & 1.32 & 1.09 \\
\hline & 298.8 & 90.9 & 6 & 8.4 & 990 & 90 & 435 & 149.1 & 1.15 & 1.01 \\
\hline \multirow{2}{*}{$250 \times 90 \times 6$} & 249.5 & 89.9 & 5.99 & 7.9 & 796.5 & 45 & 445 & 148.4 & 1.22 & 1.08 \\
\hline & 249.6 & 90 & 6.01 & 7.9 & 838.4 & 90 & 445 & 148.5 & 1.03 & 0.97 \\
\hline \multirow{2}{*}{$200 \times 75 \times 5$} & 198.8 & 76 & 4.73 & 4.2 & 638 & 37.5 & 415 & 99.8 & 1.16 & 0.96 \\
\hline & 198.7 & 75.9 & 4.72 & 4.2 & 675.2 & 75 & 415 & 100.1 & 1.00 & 0.86 \\
\hline \multirow{2}{*}{$125 \times 65 \times 4$} & 125 & 65.45 & 3.84 & 3.9 & 407.6 & 32.5 & 405 & 64.1 & 1.15 & 1.14 \\
\hline & 125 & 65.55 & 3.83 & 3.9 & 440.1 & 65 & 405 & 60.0 & 0.93 & 0.92 \\
\hline \multirow{2}{*}{$100 \times 50 \times 4$} & 99.2 & 50.4 & 3.83 & 4.1 & 325 & 25 & 440 & 66.3 & 1.15 & 1.31 \\
\hline & 99.3 & 50.4 & 3.83 & 4.1 & 350 & 50 & 440 & 58.3 & 0.87 & 1.00 \\
\hline \multirow{2}{*}{$75 \times 40 \times 4$} & 74.6 & 40.5 & 3.84 & 3.9 & 243 & 20 & 450 & 54.9 & 0.91 & 1.25 \\
\hline & 74.5 & 40.5 & 3.84 & 3.9 & 263.8 & 40 & 450 & 51.3 & 0.74 & 1.01 \\
\hline \multicolumn{9}{|c|}{ Mean } & 1.05 & 1.05 \\
\hline \multicolumn{9}{|c|}{$\mathrm{COV}$} & 0.16 & 0.13 \\
\hline
\end{tabular}

Elastic modulus $=203,000 \mathrm{MPa}$ 
Table 6: Test specimen details and results for ETF load case

\begin{tabular}{|c|c|c|c|c|c|c|c|c|}
\hline Test & Section & $\mathrm{d}(\mathrm{mm})$ & $\mathrm{b}_{\mathrm{f}}(\mathrm{mm})$ & $\mathrm{t}_{\mathrm{w}}(\mathrm{mm})$ & $r_{i}(\mathrm{~mm})$ & $\mathrm{L}(\mathrm{mm})$ & $1_{b}(\mathrm{~mm})$ & $\begin{array}{c}\text { Ultimate } \\
\text { load } \\
(\mathrm{kN})\end{array}$ \\
\hline E-1 & \multirow{5}{*}{$250 \times 90 \times 6$} & 249.0 & 90.1 & 6.04 & 8.0 & 375 & 50 & 49.2 \\
\hline E-2 & & 252.2 & 89.8 & 6.01 & 8.0 & 501 & 50 & 52.1 \\
\hline E-3 & & 251.9 & 89.3 & 6.02 & 8.0 & 626 & 50 & 52.7 \\
\hline E-4 & & 249.4 & 90.0 & 6.04 & 8.0 & 750 & 50 & 50.8 \\
\hline E-5 & & 251.1 & 90.1 & 6.03 & 8.0 & 1000 & 50 & 52.0 \\
\hline E-6 & \multirow{3}{*}{$200 \times 75 \times 6$} & 198.4 & 75.1 & 5.86 & 8.0 & 600 & 25 & $48.1^{\mathrm{C}+}$ \\
\hline E-7 & & 197.9 & 74.2 & 5.87 & 8.0 & 600 & 50 & 48.1 \\
\hline E-8 & & 197.7 & 75.2 & 5.88 & 8.0 & 600 & 100 & 53.9 \\
\hline E-9 & \multirow{3}{*}{$200 \times 75 \times 5$} & 198.5 & 76.1 & 4.71 & 4.5 & 600 & 150 & 39.6 \\
\hline E-10 & & 198.4 & 76.1 & 4.70 & 4.5 & 600 & 50 & 31.6 \\
\hline E-11 & & 197.2 & 75.9 & 4.69 & 4.5 & 600 & 100 & 35.4 \\
\hline E-12 & \multirow{3}{*}{$150 \times 75 \times 5$} & 152.2 & 75.1 & 4.68 & 4.0 & 451 & 150 & 48.2 \\
\hline E-13 & & 150.4 & 75.1 & 4.67 & 4.0 & 450 & 50 & 34.1 \\
\hline E-14 & & 152.0 & 74.6 & 4.70 & 4.0 & 450 & 100 & 41.6 \\
\hline E-15 & $125 \times 65 \times 4$ & 125.0 & 64.9 & 3.83 & 4.0 & 375 & 50 & 26.3 \\
\hline E-16 & \multirow{6}{*}{$100 \times 50 \times 4$} & 100.0 & 50.1 & 3.78 & 4.0 & 301 & 100 & 28.0 \\
\hline E-17 & & 100.6 & 49.9 & 3.79 & 4.0 & 199 & 50 & $23.8^{*}$ \\
\hline E-18 & & 100.1 & 50.8 & 3.79 & 4.0 & 300 & 50 & 23.3 \\
\hline E-19 & & 100.2 & 50.4 & 3.81 & 4.0 & 300 & 50 & $22.6^{\#}$ \\
\hline E-20 & & 100.1 & 50.6 & 3.79 & 4.0 & 175 & 25 & $21.0^{* *}$ \\
\hline E-21 & & 100.0 & 49.2 & 3.80 & 4.0 & 200 & 50 & $22.9^{\# \#}$ \\
\hline E-22 & $75 \times 40 \times 4$ & 74.8 & 39.7 & 3.79 & 4.0 & 225 & 50 & 24.1 \\
\hline
\end{tabular}

\# - Test E-19 is a repeat of Test E-18; 
\#\# - Test E-21 is a repeat of Test E-17;

* - Corresponding Young and Hancock's [20] value is $24.8 \mathrm{kN}$;

** - Corresponding Young and Hancock's [20] value is $22.6 \mathrm{kN}$;

C - Combined flange crushing and web crippling;

+ - Test was stopped prematurely. 
Table 7: Test specimen details and results for ITF load case

\begin{tabular}{|c|c|c|c|c|c|c|c|c|}
\hline Test & Section & $\mathrm{d}(\mathrm{mm})$ & $\mathrm{b}_{\mathrm{f}}(\mathrm{mm})$ & $\mathrm{t}_{\mathrm{w}}(\mathrm{mm})$ & $\mathrm{r}_{\mathrm{i}}(\mathrm{mm})$ & $\mathrm{L}(\mathrm{mm})$ & $\mathrm{l}_{\mathrm{b}}(\mathrm{mm})$ & $\begin{array}{l}\text { Ultimate } \\
\text { load }(\mathrm{kN})\end{array}$ \\
\hline $\mathrm{I}-1$ & \multirow{5}{*}{$250 \times 90 \times 6$} & 251.2 & 89.6 & 5.98 & 8.00 & 750 & 150 & 144.7 \\
\hline $\mathrm{I}-2$ & & 249.2 & 90.7 & 5.99 & 8.00 & 875 & 150 & 154.2 \\
\hline I-3 & & 250.4 & 90.1 & 6.02 & 8.00 & 1000 & 150 & 157.1 \\
\hline $\mathrm{I}-4$ & & 251.6 & 91.2 & 6.01 & 8.00 & 1250 & 150 & 160.5 \\
\hline $\mathrm{I}-5$ & & 250.4 & 90.4 & 6.01 & 8.00 & 1500 & 150 & 164.9 \\
\hline I-6 & \multirow{2}{*}{$200 \times 75 \times 6$} & 198.1 & 74.5 & 5.97 & 8.00 & 1000 & 150 & 155.0 \\
\hline $\mathrm{I}-7$ & & 200.8 & 75.7 & 5.88 & 8.00 & 1000 & 100 & 152.2 \\
\hline $\mathrm{I}-8$ & \multirow{3}{*}{$200 \times 75 \times 5$} & 197.1 & 74.7 & 4.70 & 4.50 & 1000 & 150 & 105.2 \\
\hline I-9 & & 201.5 & 75.9 & 4.70 & 4.50 & 1000 & 50 & $97.0^{\mathrm{C}+}$ \\
\hline I-10 & & 199.1 & 75.1 & 4.68 & 4.50 & 1000 & 100 & 101.8 \\
\hline I-11 & \multirow{3}{*}{$150 \times 75 \times 5$} & 149.1 & 75.1 & 4.66 & 4.00 & 750 & 25 & $96.8^{\mathrm{C}+}$ \\
\hline $\mathrm{I}-12$ & & 149.5 & 75.1 & 4.68 & 4.00 & 750 & 50 & $100.3^{C}$ \\
\hline $\mathrm{I}-13$ & & 152.5 & 75.0 & 4.66 & 4.00 & 750 & 100 & 102.7 \\
\hline I-14 & \multirow{2}{*}{$125 \times 65 \times 4$} & 123.3 & 64.6 & 3.84 & 4.00 & 625 & 100 & 72.7 \\
\hline I-15 & & 123.8 & 64.8 & 3.80 & 4.00 & 625 & 50 & $73.7^{C}$ \\
\hline I-16 & \multirow{4}{*}{$100 \times 50 \times 4$} & 100.1 & 50.5 & 3.81 & 4.00 & 499 & 100 & 66.1 \\
\hline $\mathrm{I}-17$ & & 99.8 & 50.8 & 3.84 & 4.00 & 350 & 50 & $59.0^{*}$ \\
\hline I-18 & & 99.8 & 49.7 & 3.79 & 4.00 & 500 & 50 & 63.1 \\
\hline I-19 & & 100.2 & 50.0 & 3.82 & 4.00 & 325 & 25 & $62.3^{\mathrm{C}^{* *}}$ \\
\hline I-20 & $75 \times 40 \times 4$ & 75.9 & 39.8 & 3.80 & 4.00 & 375 & 50 & 59.4 \\
\hline
\end{tabular}

* - Corresponding Young and Hancock's [20] value is $58.3 \mathrm{kN}$;

** - Corresponding Young and Hancock's [20] value is $66.3 \mathrm{kN}$;

C - Combined flange crushing and web crippling;

+ - Test stopped prematurely. 
Table 8: Mechanical properties of steel used in test specimens

\begin{tabular}{|c|c|c|c|c|c|c|c|}
\hline Section & $250 \times 90 \times 6$ & $200 \times 75 \times 6$ & $200 \times 75 \times 5$ & $150 \times 75 \times 5$ & $125 \times 65 \times 4$ & $100 \times 50 \times 4$ & $75 \times 40 \times 4$ \\
\hline $\begin{array}{c}\text { Yield strength } \\
(\mathrm{MPa})\end{array}$ & 470 & 477 & 477 & 468 & 494 & 449 & 480 \\
\hline $\begin{array}{c}\text { Ultimate strength } \\
(\mathrm{MPa})\end{array}$ & 562 & 544 & 544 & 547 & 561 & 539 & 563 \\
\hline
\end{tabular}

Elastic modulus $=200000 \mathrm{MPa}$

Table 9: Comparison of test results with predictions for ETF load case

\begin{tabular}{|c|c|c|c|c|c|c|c|c|c|c|}
\hline \multirow[b]{2}{*}{ Test } & \multirow[b]{2}{*}{ Section } & \multirow{2}{*}{$\begin{array}{c}\mathrm{L} \\
(\mathrm{mm})\end{array}$} & \multirow{2}{*}{$\begin{array}{c}\mathrm{l}_{\mathrm{b}} \\
(\mathrm{mm})\end{array}$} & Test & \multicolumn{6}{|c|}{ Ultimate load ratios (Test/Predicted) } \\
\hline & & & & $\begin{array}{l}\text { ultimate } \\
\text { load }(\mathrm{kN})\end{array}$ & $\begin{array}{c}\text { AS/NZS } \\
4600\end{array}$ & $\begin{array}{l}\text { Prop. } \\
\text { 1(a) }\end{array}$ & [20] & $\begin{array}{c}\text { Prop. } \\
2\end{array}$ & $\begin{array}{c}\text { Prop. } \\
3\end{array}$ & $\begin{array}{c}\text { Prop. } \\
4\end{array}$ \\
\hline E-4 & $250 \times 90 \times 6$ & 750 & 50 & 50.8 & 0.88 & 1.06 & 1.10 & 1.19 & 1.02 & 1.03 \\
\hline E-7 & \multirow{2}{*}{$200 \times 75 \times 6$} & 600 & 50 & 48.1 & 0.86 & 1.00 & 1.11 & 1.12 & 0.99 & 1.00 \\
\hline E-8 & & 600 & 100 & 53.9 & 0.79 & 0.95 & 0.85 & 1.06 & 0.94 & 0.95 \\
\hline E-9 & \multirow{3}{*}{$200 \times 75 \times 5$} & 600 & 150 & 39.6 & 0.73 & 0.92 & 0.53 & 0.91 & 0.94 & 0.96 \\
\hline E-10 & & 600 & 50 & 31.6 & 0.81 & 0.99 & 0.81 & 0.97 & 0.99 & 1.01 \\
\hline E-11 & & 600 & 100 & 35.4 & 0.74 & 0.93 & 0.62 & 0.93 & 0.95 & 0.97 \\
\hline E-12 & \multirow{3}{*}{$150 \times 75 \times 5$} & 451 & 150 & 48.2 & 0.89 & 1.08 & 0.58 & 0.90 & 1.07 & 1.09 \\
\hline E-13 & & 450 & 50 & 34.1 & 0.89 & 1.02 & 0.84 & 0.90 & 1.04 & 1.05 \\
\hline E-14 & & 450 & 100 & 41.6 & 0.87 & 1.03 & 0.66 & 0.90 & 1.05 & 1.07 \\
\hline E-15 & $125 \times 65 \times 4$ & 375 & 50 & 26.3 & 0.92 & 1.08 & 0.93 & 1.06 & 1.12 & 1.13 \\
\hline E-16 & \multirow{2}{*}{$100 \times 50 \times 4$} & 301 & 100 & 28.0 & 0.89 & 1.04 & 0.69 & 0.99 & 0.98 & 0.99 \\
\hline E-18 & & 300 & 50 & 22.9 & 0.89 & 1.01 & 0.91 & 1.03 & 0.99 & 1.00 \\
\hline E-22 & $75 \times 40 \times 4$ & 225 & 50 & 24.1 & 0.88 & 0.95 & 0.92 & 1.08 & 0.95 & 0.95 \\
\hline \multicolumn{5}{|c|}{ Mean } & 0.85 & 1.00 & 0.82 & 1.01 & 1.00 & 1.01 \\
\hline \multicolumn{5}{|c|}{$\mathrm{COV}$} & 0.07 & 0.05 & 0.22 & 0.09 & 0.05 & 0.06 \\
\hline
\end{tabular}


Table 10: Comparison of test results with predictions for ITF load case

\begin{tabular}{|c|c|c|c|c|c|c|c|c|c|c|}
\hline \multirow[b]{2}{*}{ Test } & \multirow[b]{2}{*}{ Section } & \multirow{2}{*}{$\begin{array}{c}\mathrm{L} \\
(\mathrm{mm})\end{array}$} & \multirow{2}{*}{$\begin{array}{c}\mathrm{l}_{\mathrm{b}} \\
(\mathrm{mm})\end{array}$} & & \multicolumn{6}{|c|}{ Ultimate load ratios (Test/Predicted) } \\
\hline & & & & $\begin{array}{l}\text { ultimate } \\
\text { load }(\mathrm{kN})\end{array}$ & $\begin{array}{c}\text { AS/NZS } \\
4600\end{array}$ & $\begin{array}{l}\text { Prop. } \\
1 \text { (a) }\end{array}$ & {$[20]$} & $\begin{array}{c}\text { Prop. } \\
2\end{array}$ & $\begin{array}{c}\text { Prop. } \\
3\end{array}$ & $\begin{array}{c}\text { Prop } \\
4\end{array}$ \\
\hline I-4 & $250 \times 90 \times 6$ & 1250 & 150 & 160.5 & 0.94 & 1.03 & 0.88 & 1.10 & 1.00 & 0.99 \\
\hline I-6 & \multirow{2}{*}{$200 \times 75 \times 6$} & 1000 & 150 & 155.0 & 0.87 & 0.97 & 0.89 & 1.00 & 0.93 & 0.92 \\
\hline $\mathrm{I}-7$ & & 1000 & 100 & 152.2 & 0.99 & 1.03 & 1.01 & 1.14 & 1.03 & 1.01 \\
\hline $\mathrm{I}-8$ & \multirow{2}{*}{$200 \times 75 \times 5$} & 1000 & 150 & 105.2 & 0.78 & 1.01 & 0.69 & 0.88 & 1.00 & 0.99 \\
\hline $\mathrm{I}-10$ & & 1000 & 100 & 101.8 & 0.86 & 1.04 & 0.76 & 0.97 & 1.07 & 1.05 \\
\hline $\mathrm{I}-13$ & $150 \times 75 \times 5$ & 750 & 100 & 102.7 & 0.81 & 1.03 & 0.77 & 0.87 & 1.05 & 1.03 \\
\hline I-14 & $125 \times 65 \times 4$ & 625 & 100 & 72.7 & 0.82 & 1.01 & 0.81 & 0.91 & 1.01 & 1.00 \\
\hline I-16 & \multirow{2}{*}{$100 \times 50 \times 4$} & 499 & 100 & 66.1 & 0.82 & 1.01 & 0.87 & 0.93 & 0.95 & 0.92 \\
\hline I-18 & & 500 & 50 & 63.1 & 0.94 & 1.05 & 1.06 & 1.12 & 1.07 & 1.04 \\
\hline I-20 & $75 \times 40 \times 4$ & 375 & 50 & 59.4 & 0.80 & 0.90 & 1.05 & 1.06 & 0.94 & 0.90 \\
\hline \multicolumn{5}{|c|}{ Mean } & 0.86 & 1.01 & 0.88 & 1.00 & 1.00 & 0.99 \\
\hline \multicolumn{5}{|c|}{$\mathrm{COV}$} & 0.08 & 0.04 & 0.15 & 0.10 & 0.05 & 0.05 \\
\hline
\end{tabular}


Table 11: Proposed coefficients based on AS/NZS 4600 design rules

\begin{tabular}{|c|c|c|c|c|c|c|c|c|}
\hline $\begin{array}{c}\text { Load } \\
\text { case }\end{array}$ & Coefficients & $\mathrm{C}$ & $\mathrm{C}_{\mathrm{r}}$ & $\mathrm{C}_{\mathrm{l}}$ & $\mathrm{C}_{\mathrm{w}}$ & Mean & $\mathrm{COV}$ & $\phi_{\mathrm{w}}$ \\
\hline \multirow{4}{*}{ ETF } & AS/NZS 4600 & 2 & 0.11 & 0.37 & 0.01 & 0.85 & 0.07 & 0.76 \\
\cline { 2 - 9 } & Proposal 1(a) & 2.93 & 0.19 & 0.26 & 0.05 & 1.00 & 0.05 & 0.91 \\
\cline { 2 - 9 } & Proposal 1(b) & 3.05 & 0.19 & 0.26 & 0.05 & 0.97 & 0.05 & 0.87 \\
\hline \multirow{3}{*}{ ITF } & AS/NZS 4600 & 13 & 0.47 & 0.25 & 0.04 & 0.86 & 0.08 & 0.76 \\
\cline { 2 - 9 } & Proposal 1(a) & 11 & 0.21 & 0.07 & 0.03 & 1.01 & 0.04 & 0.92 \\
\cline { 2 - 9 } & Proposal 1(b) & 11.6 & 0.21 & 0.07 & 0.03 & 0.96 & 0.04 & 0.87 \\
\hline
\end{tabular}

Table 12: Proposed coefficients based on Young and Hancock’s [20] design rules

\begin{tabular}{|c|c|c|c|c|c|c|c|c|}
\hline $\begin{array}{c}\text { Load } \\
\text { case }\end{array}$ & Coefficients & $\mathrm{C}_{\mathrm{a}}$ & $\mathrm{C}_{\mathrm{b}}$ & $\mathrm{e}$ & $\mathrm{i}$ & Mean & $\mathrm{COV}$ & $\phi_{\mathrm{w}}$ \\
\hline \multirow{2}{*}{ ETF } & $\begin{array}{c}\text { Young and Hancock } \\
{[20]}\end{array}$ & 1.44 & 0.0133 & 0.6 & $\mathrm{~N} / \mathrm{A}$ & 0.82 & 0.22 & 0.58 \\
\cline { 2 - 9 } & Proposal 2 & 0.706 & 0.011 & 2.5 & $\mathrm{~N} / \mathrm{A}$ & 1.01 & 0.09 & 0.88 \\
\hline \multirow{2}{*}{ ITF } & $\begin{array}{c}\text { Young and Hancock } \\
{[20]}\end{array}$ & 1.44 & 0.0133 & $\mathrm{~N} / \mathrm{A}$ & 1.4 & 0.88 & 0.15 & 0.71 \\
\cline { 2 - 9 } & \begin{tabular}{c} 
Proposal 2 \\
\cline { 2 - 9 }
\end{tabular} & 1.5 & 0.021 & N/A & 1.5 & 1.00 & 0.10 & 0.86 \\
\hline
\end{tabular}


Figure Captions

Figure 1: Cold-formed steel floor systems

Figure 2: Web crippling failure at a reaction point

Figure 3: Loading conditions for web crippling tests [2,3]

Figure 4: Young and Hancock's [20] web crippling test set-up

Figure 5: Macdonald et al.'s [21] web crippling test set-up

Figure 6: Uzzaman et al.'s [23,24] test set-up and failure modes

Figure 7: Mechanism model proposed by Young and Hancock [20]

Figure 8: Plastic hinge position and mechanism length, $\left(N_{m}\right)$ assumed by Young and Hancock [20]

Figure 9: Web crippling test set-up for ETF load case

Figure 10: Web crippling test set-up for ITF load case

Figure 11: Web crippling failure modes under ETF load case

Figure 12: Web crippling failure modes under ITF load case

Figure 13: Combined flange crushing and web crippling (Test I-9)

Figure 14: Typical load versus deflection curves

Figure 15: Section deformation during the test

Figure 16: Comparison of web crippling capacities from tests and DSM based design equations

Figure 17: Simplified method to predict the web crippling capacities of DuraGal channels 


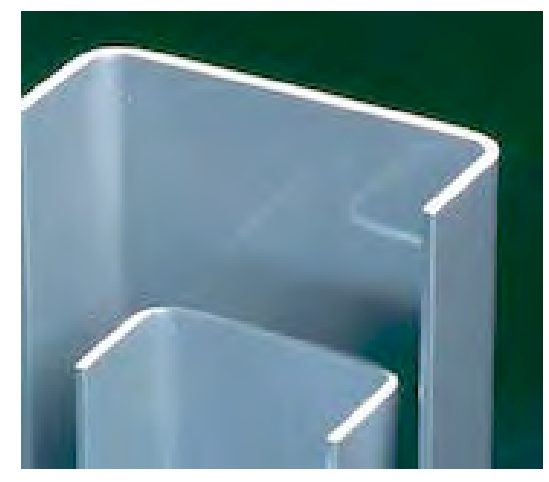

(a) Duragal channel section

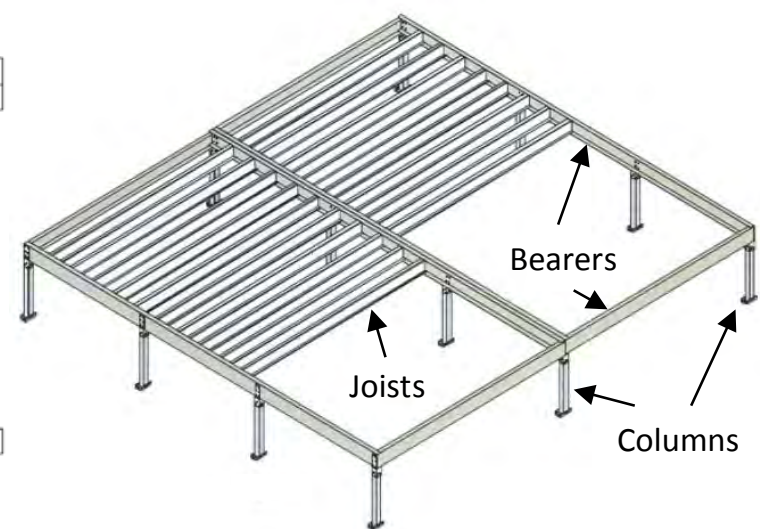

(b) Floor system

Figure 1: Cold-formed steel floor systems 


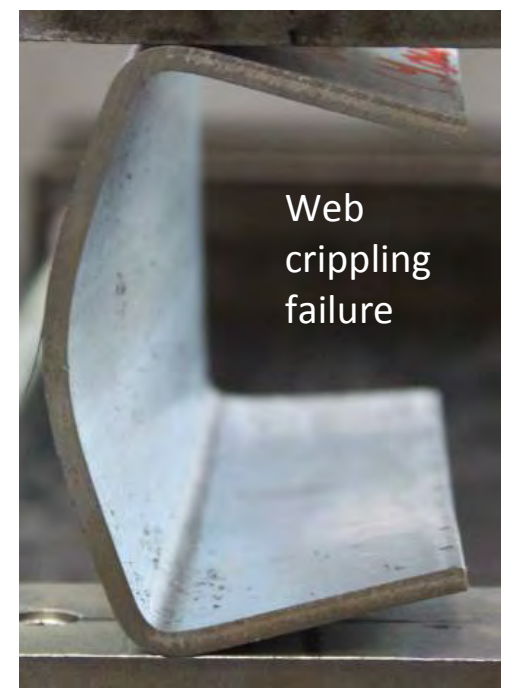

Figure 2: Web crippling failure at a reaction point 


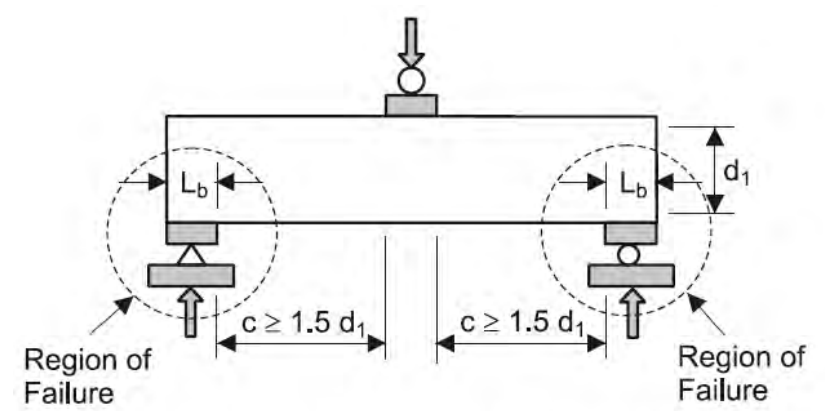

(a) End one flange loading (EOF)

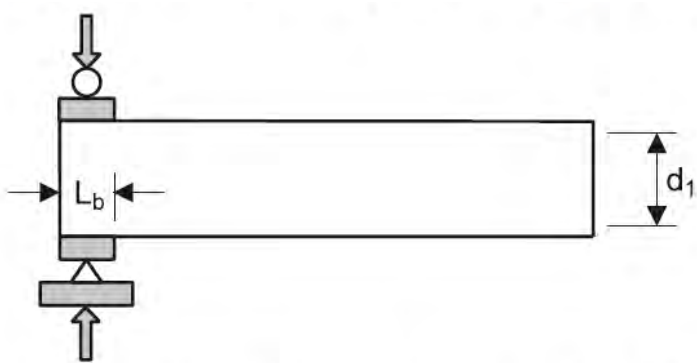

(c) End two flange loading (ETF)

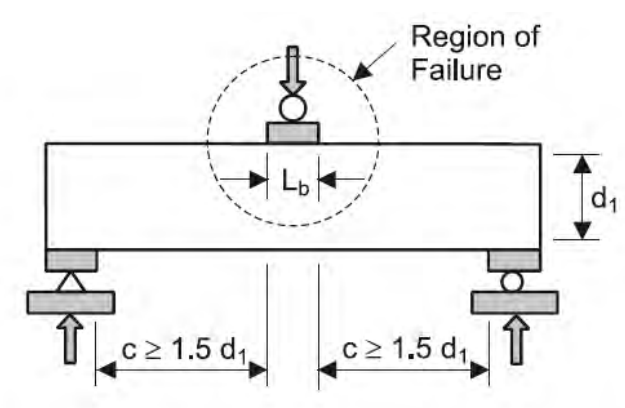

(b) Interior one flange loading (IOF)

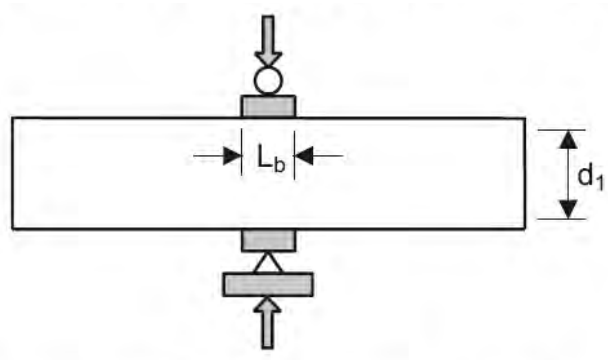

(d) Interior two flange loading (ITF)

Figure 3: Loading conditions for web crippling tests [2,3] 


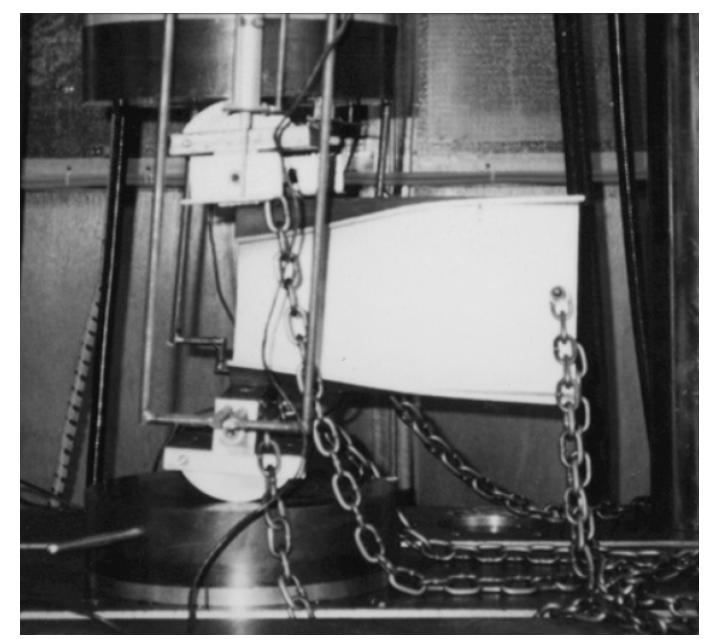

(a) ETF load case - front view

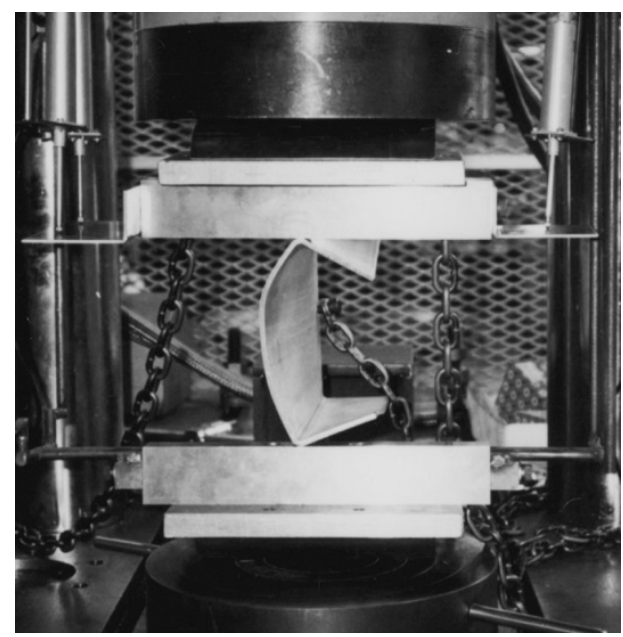

(b) ETF load case - end view

Figure 4: Young and Hancock’s [20] web crippling test set-up 


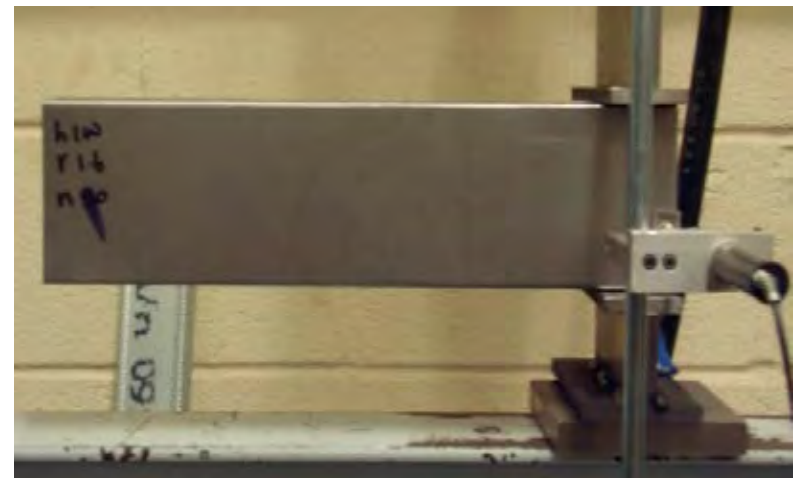

(a) ETF load case

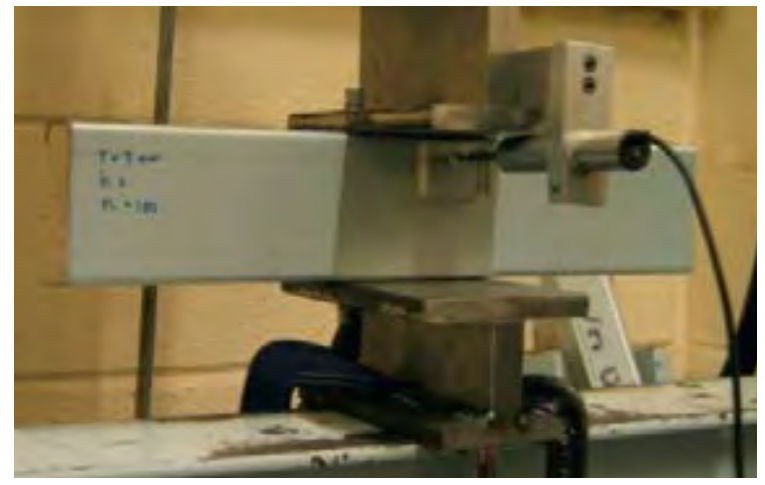

(b) ITF load case

Figure 5: Macdonald et al.'s [21] web crippling test set-up 


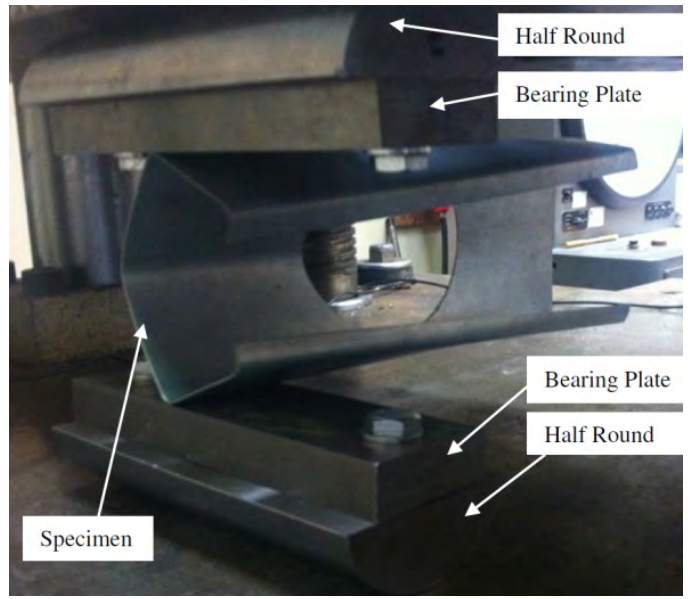

(a) ETF load case

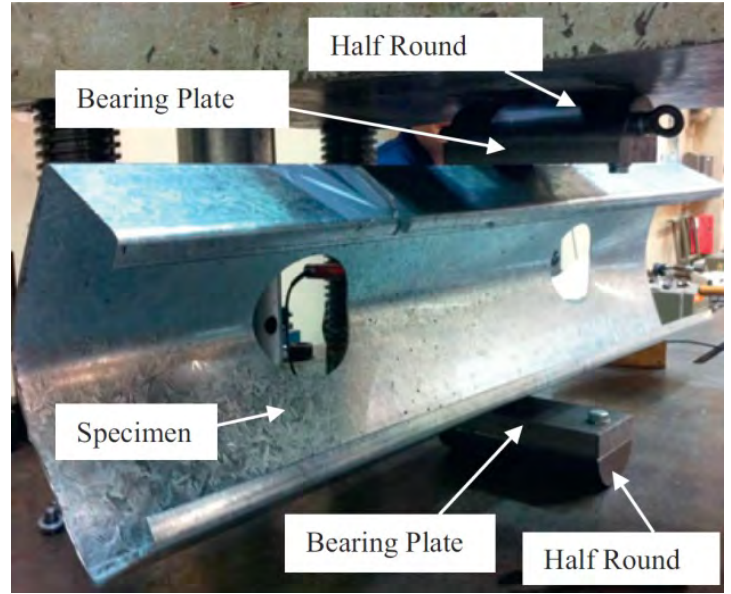

(b) ITF load case

Figure 6: Uzzaman et al.'s [23,24] test set-up and failure modes 


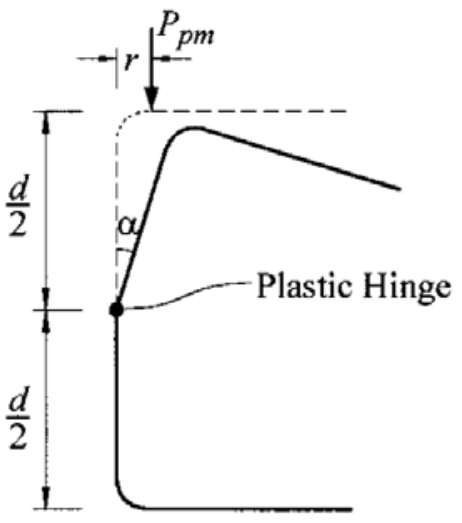

(a) One flange loading

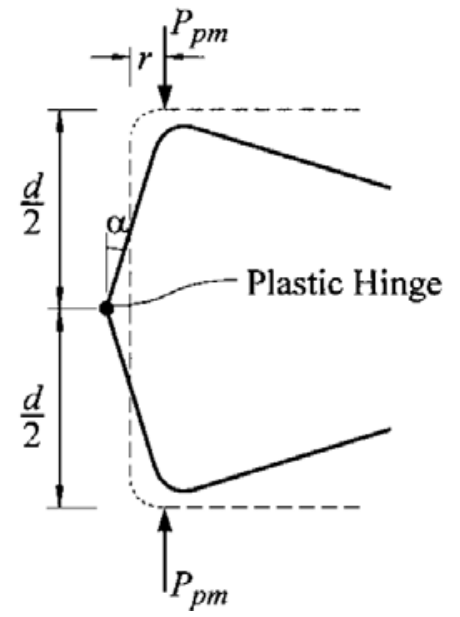

(b) Two flange loading

Figure 7: Mechanism model proposed by Young and Hancock [20] 


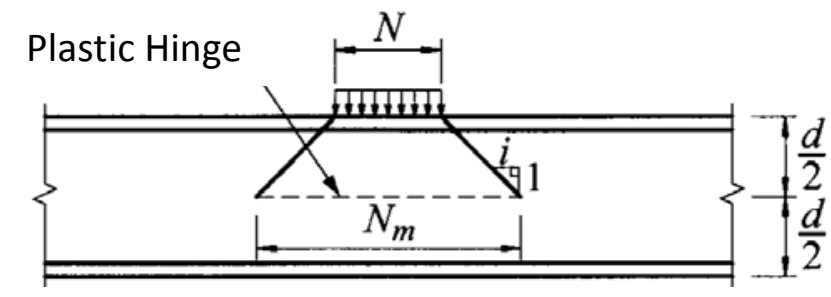

(a) Interior loading

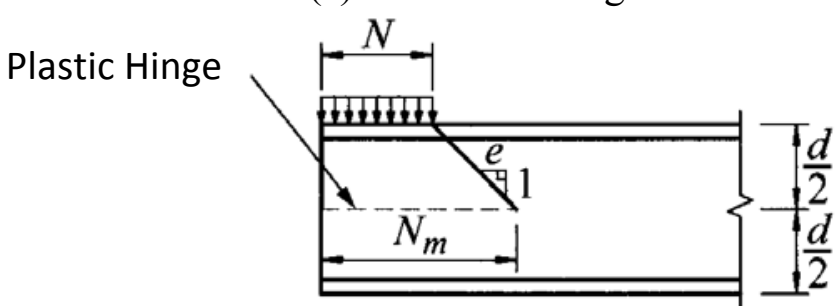

(b) End loading

Figure 8: Plastic hinge position and mechanism length, $\left(N_{m}\right)$ assumed by Young and Hancock [20] 

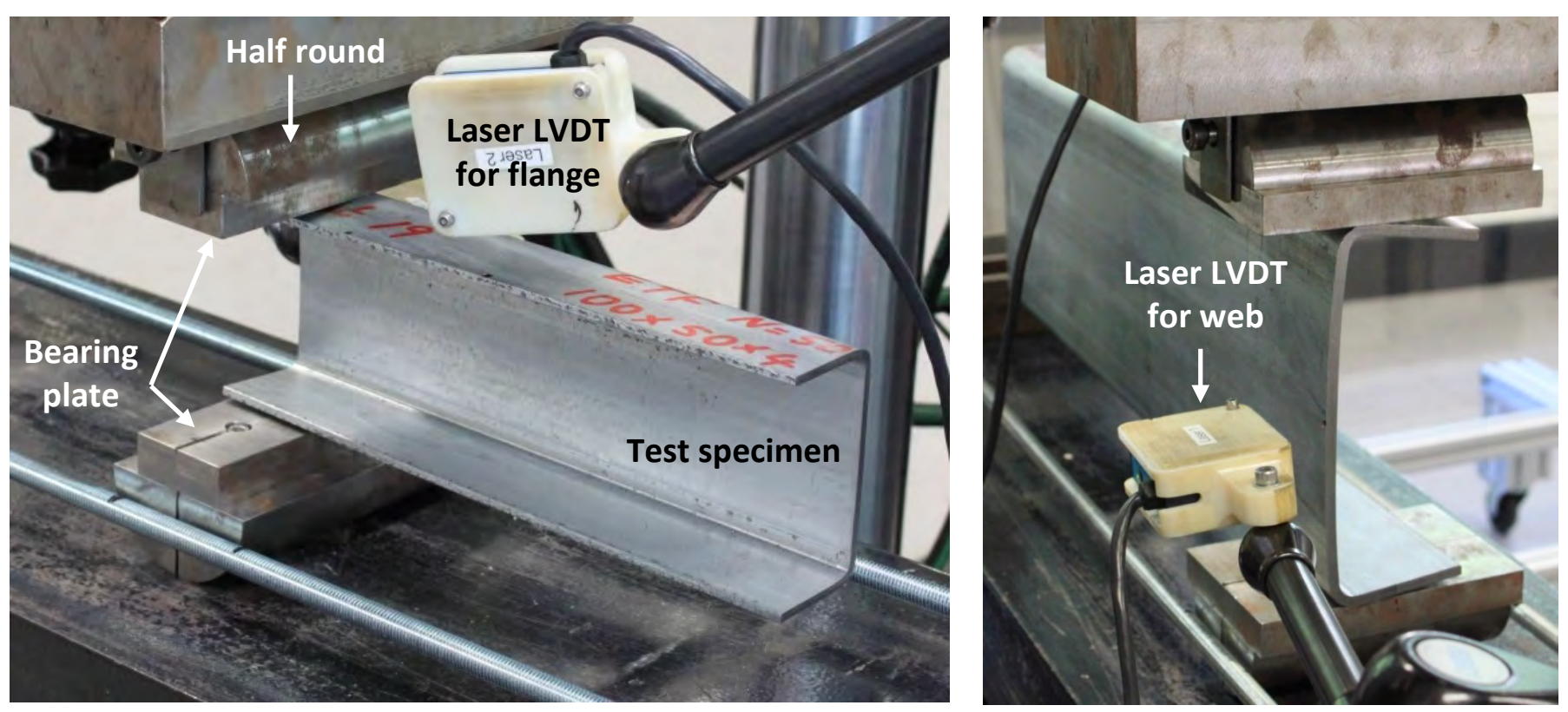

Figure 9: Web crippling test set-up for ETF load case 

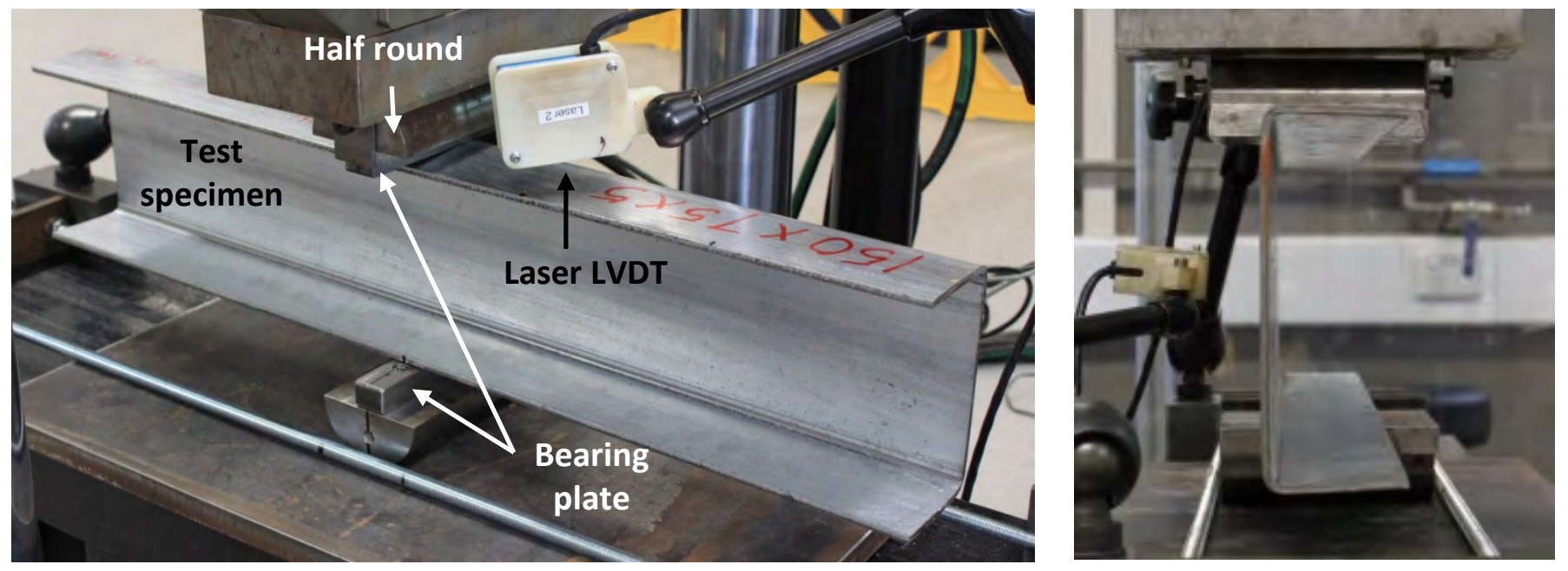

Figure 10: Web crippling test set-up for ITF load case 


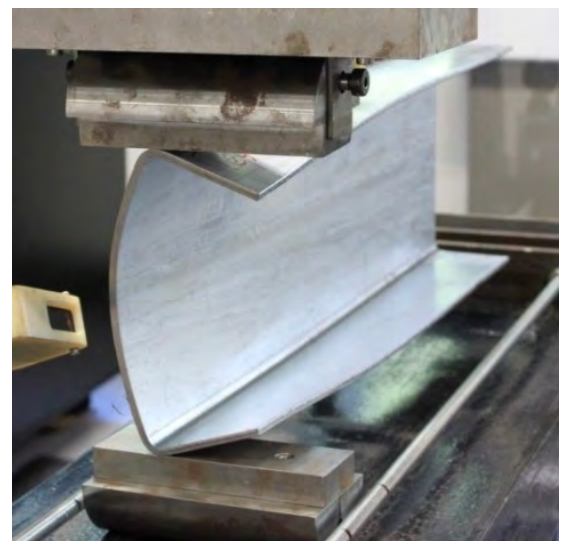

(a) Test E-10

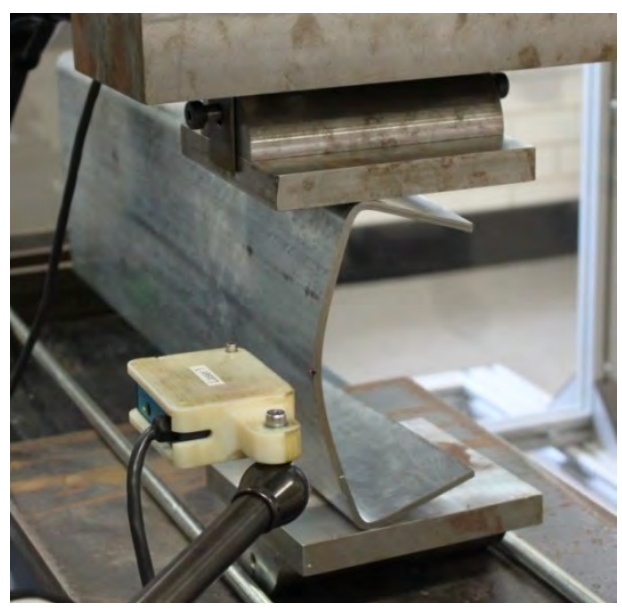

(c) Test E-9

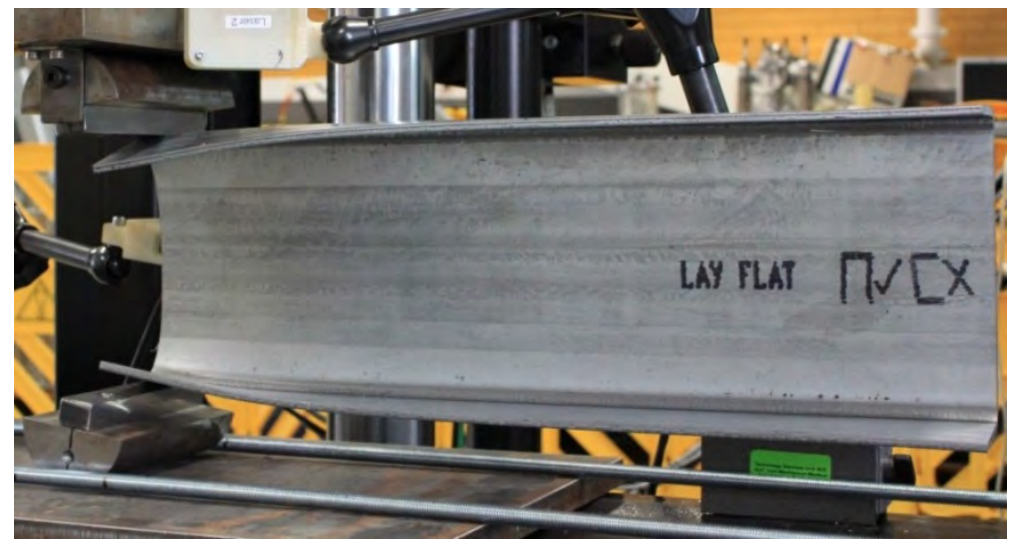

(b) Test E-6

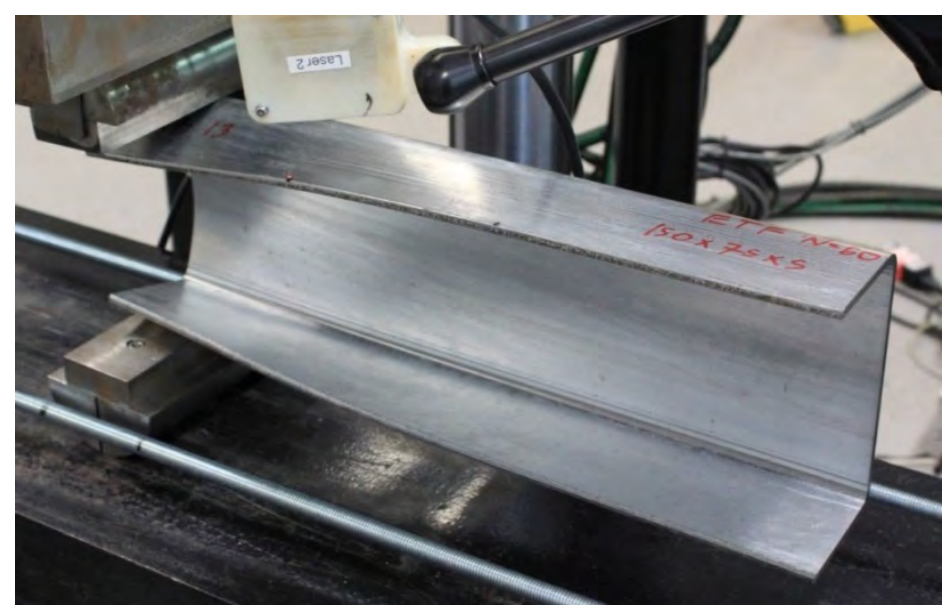

(d) Test E-13

Figure 11: Web crippling failure modes under ETF load case 


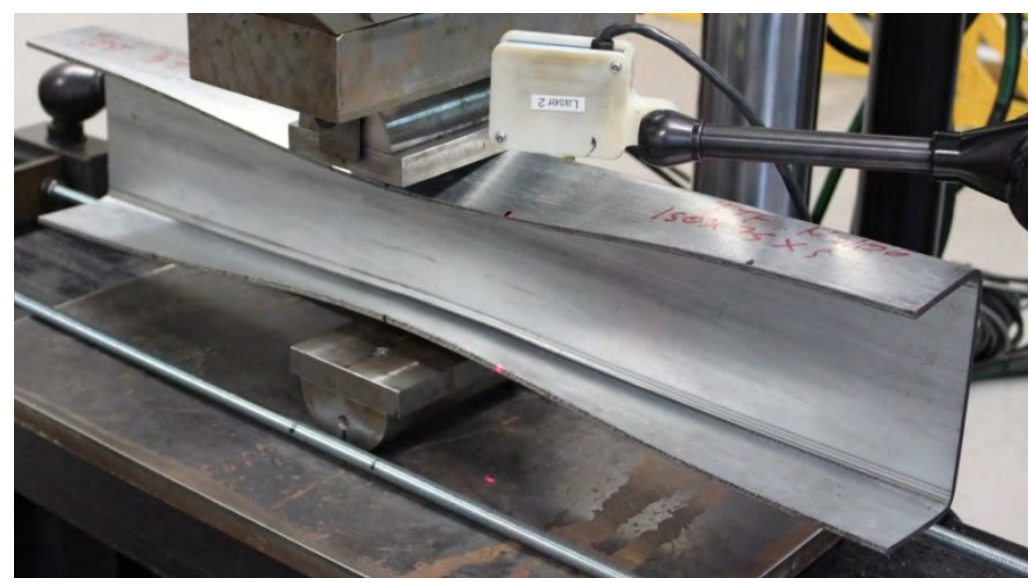

(a) Test I-13

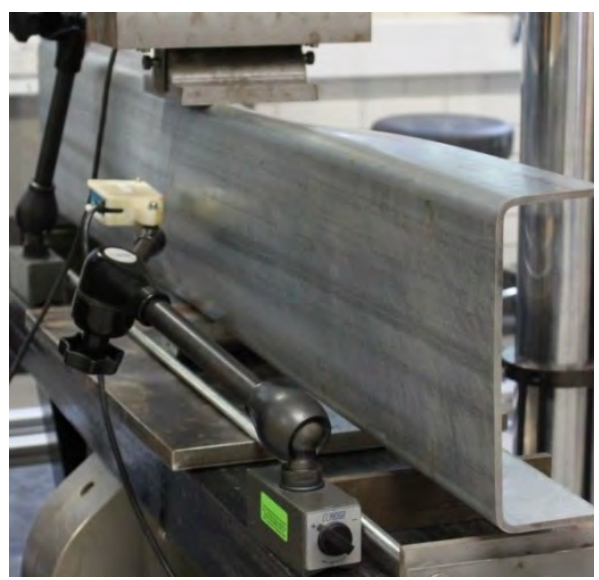

(b) Test I-5

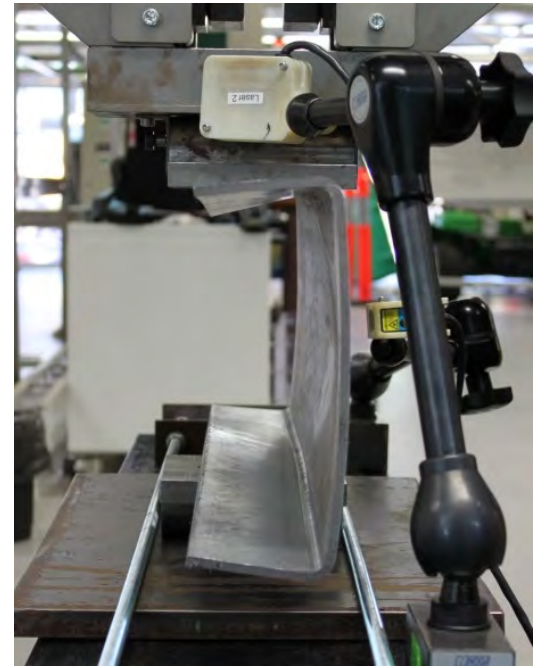

(c) Test I-2

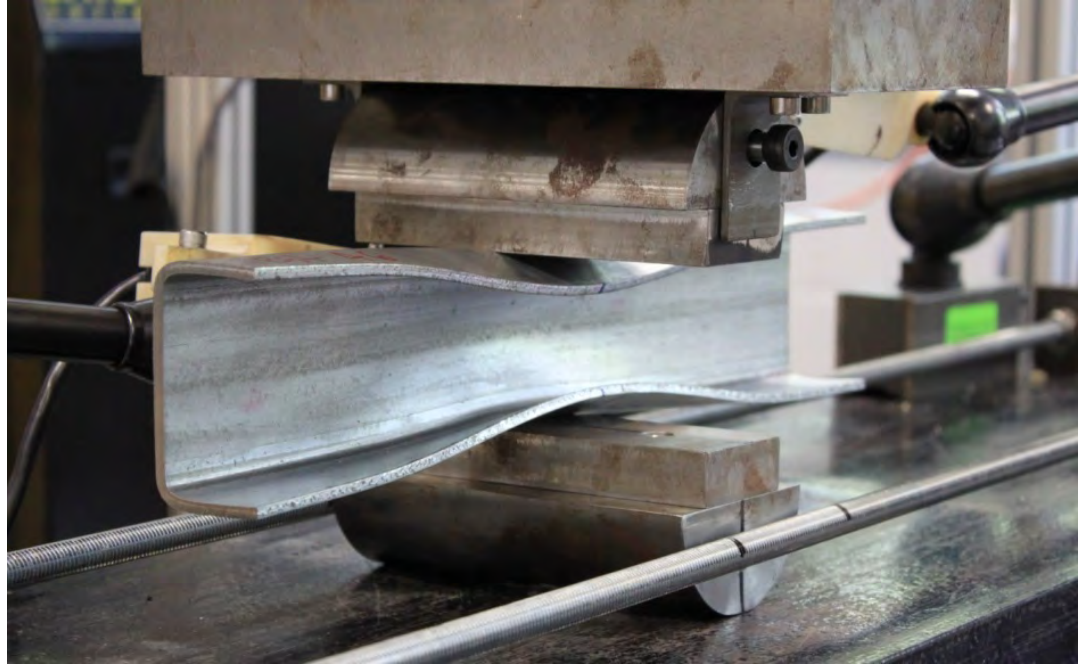

(d) Test I-20

Figure 12: Web crippling failure modes under ITF load case 

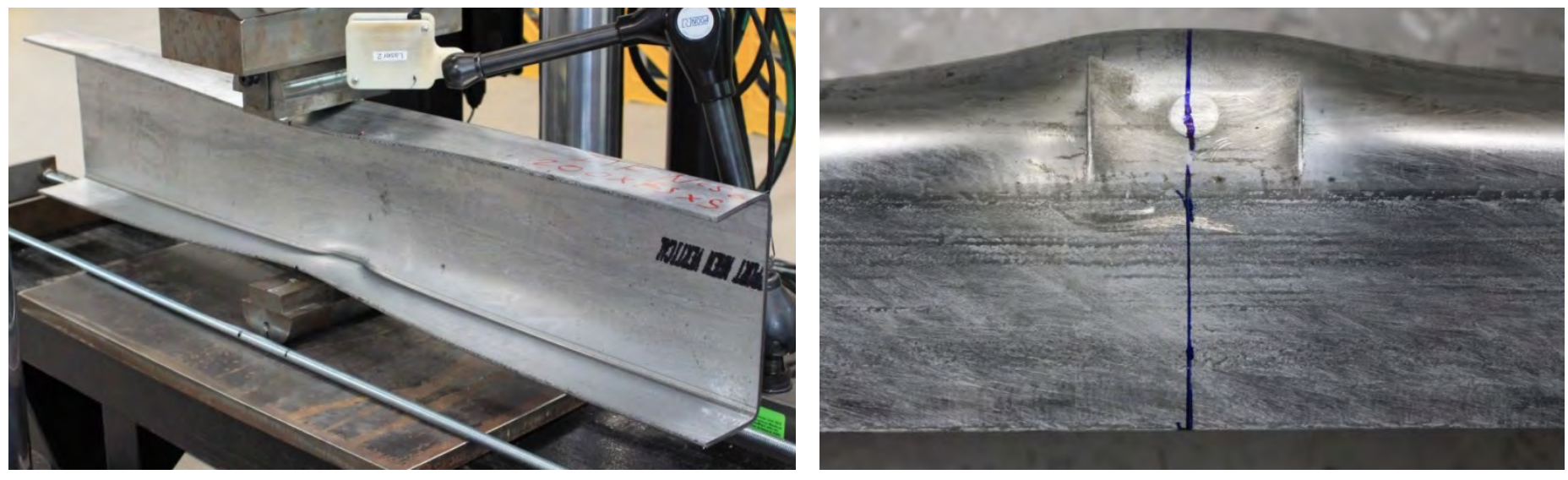

Figure 13: Combined flange crushing and web crippling (Test I-9) 


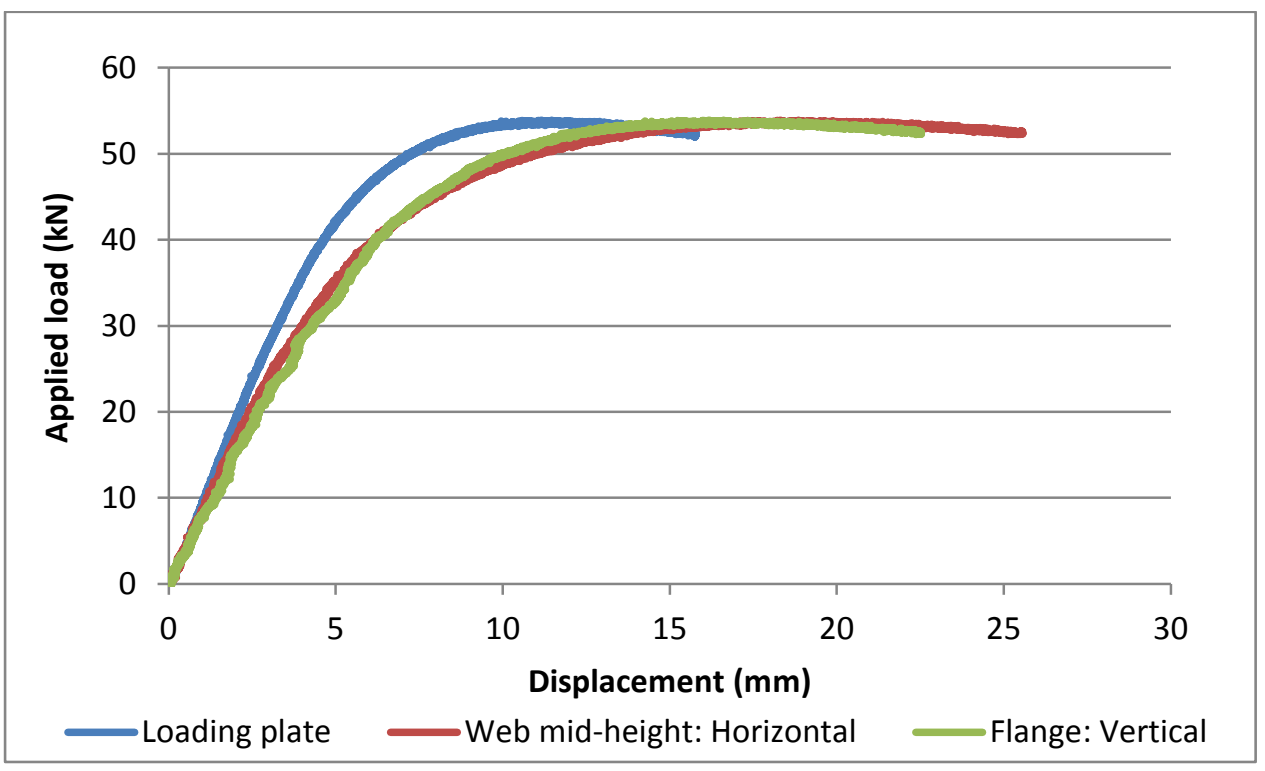

(a) ETF load case (Test E-8)

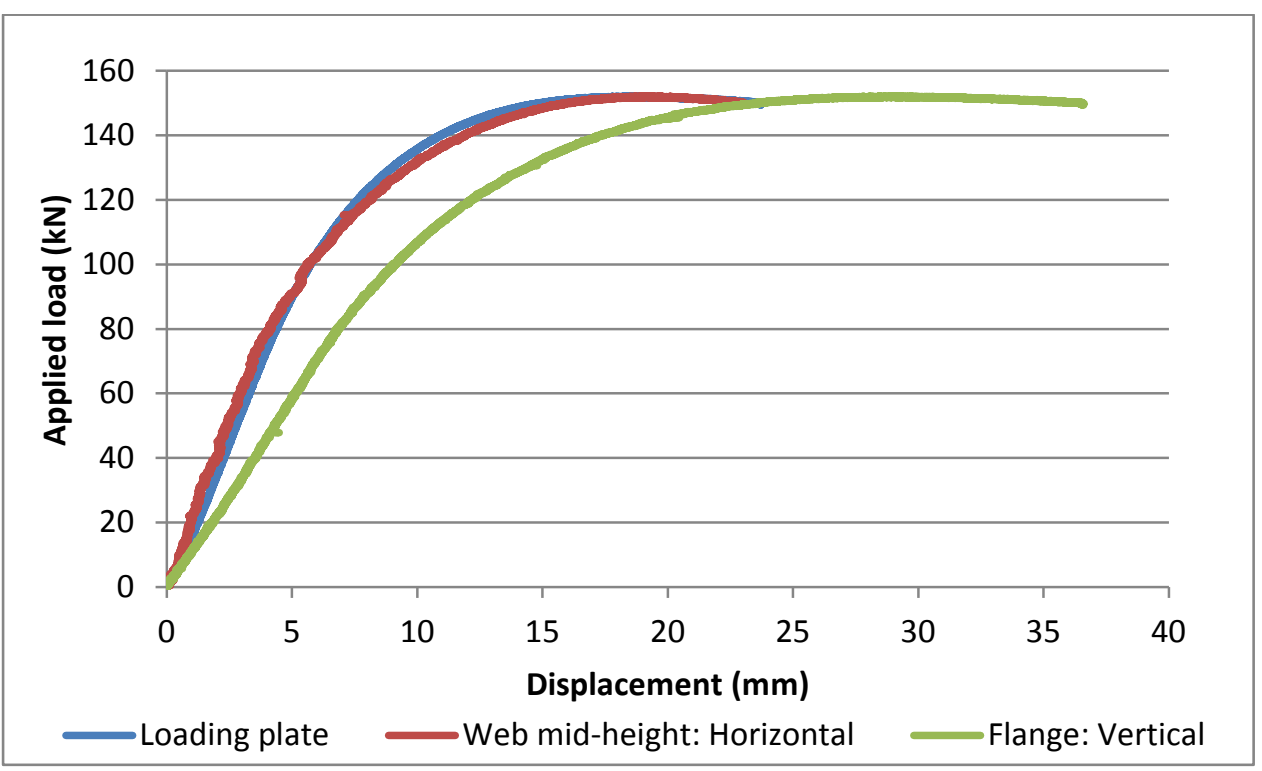

(b) ITF load case (Test I-7)

Figure 14: Typical load versus deflection curves 


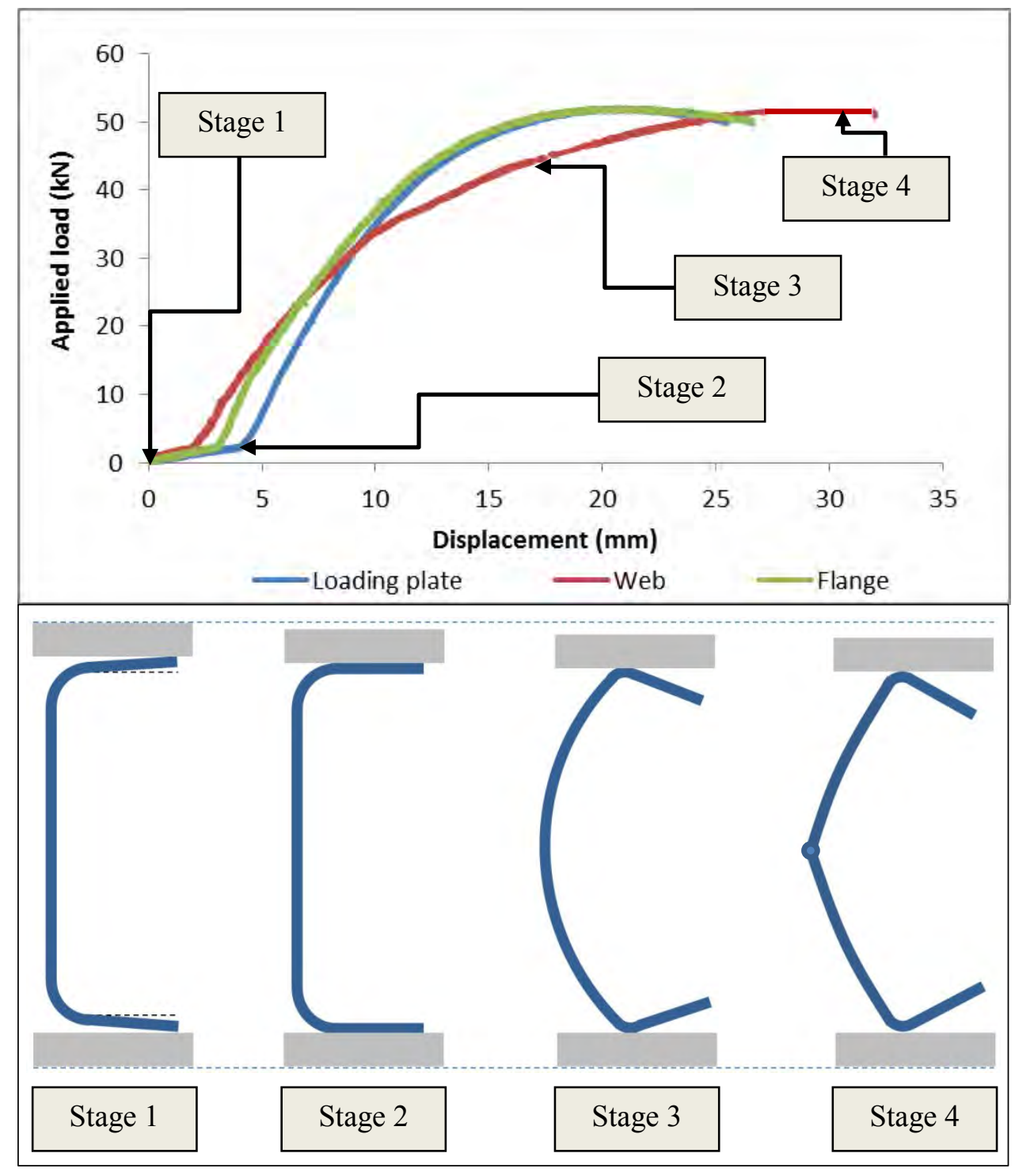

Figure 15: Section deformation during the test 


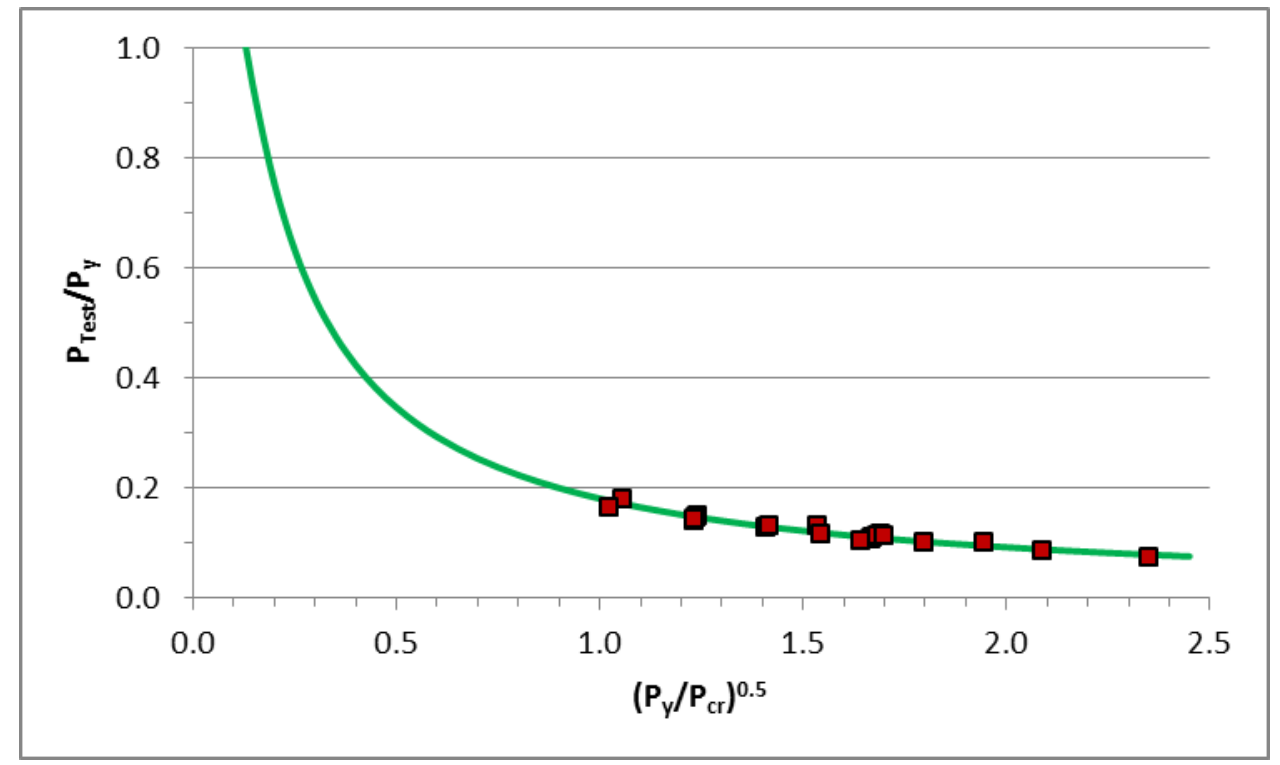

(a) ETF load case

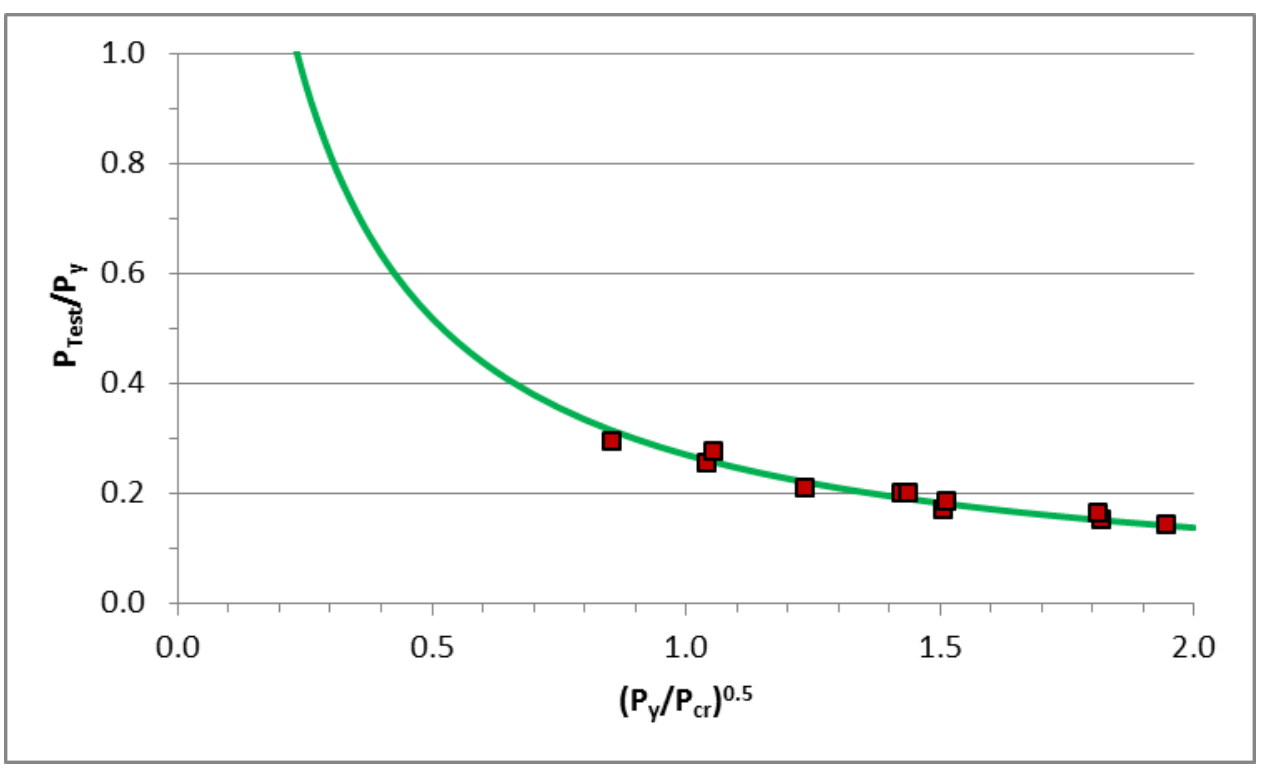

(b) ITF load case

Figure 16: Comparison of web crippling capacities from tests and DSM based design equations 


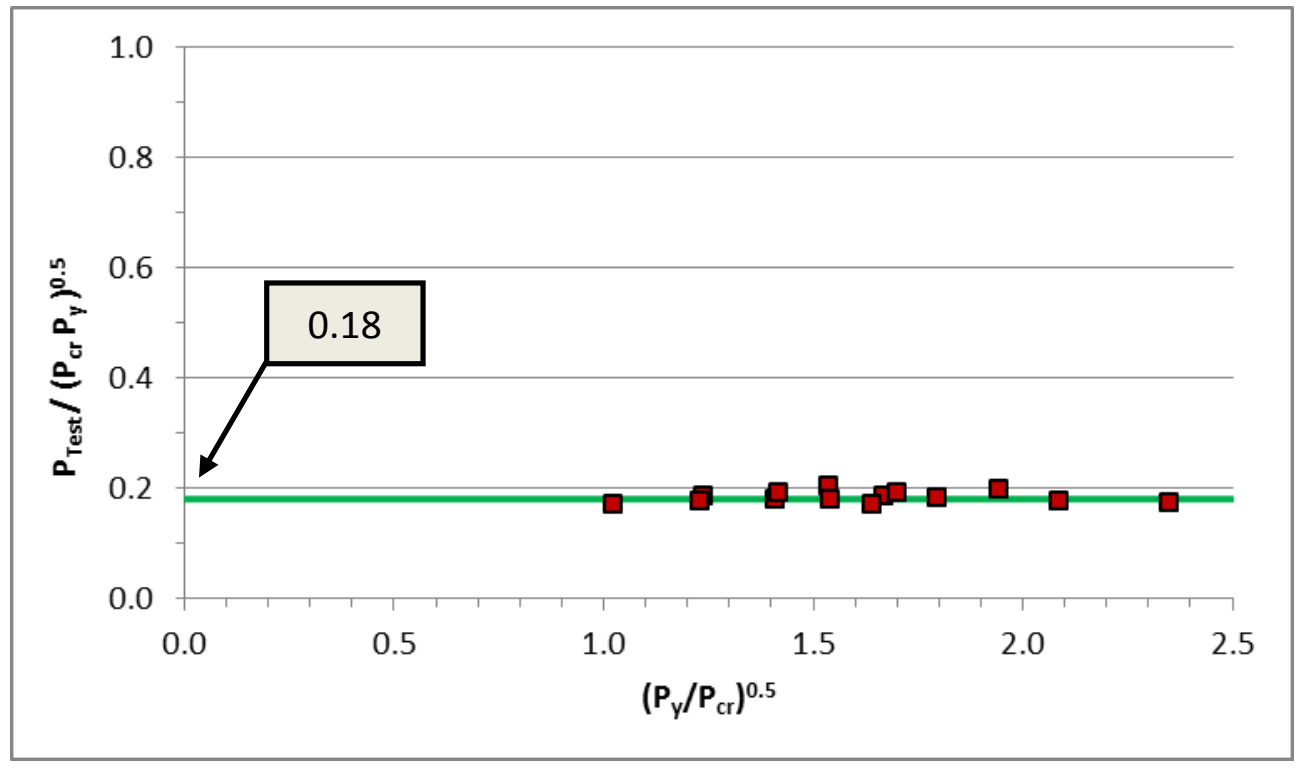

(a) ETF load case

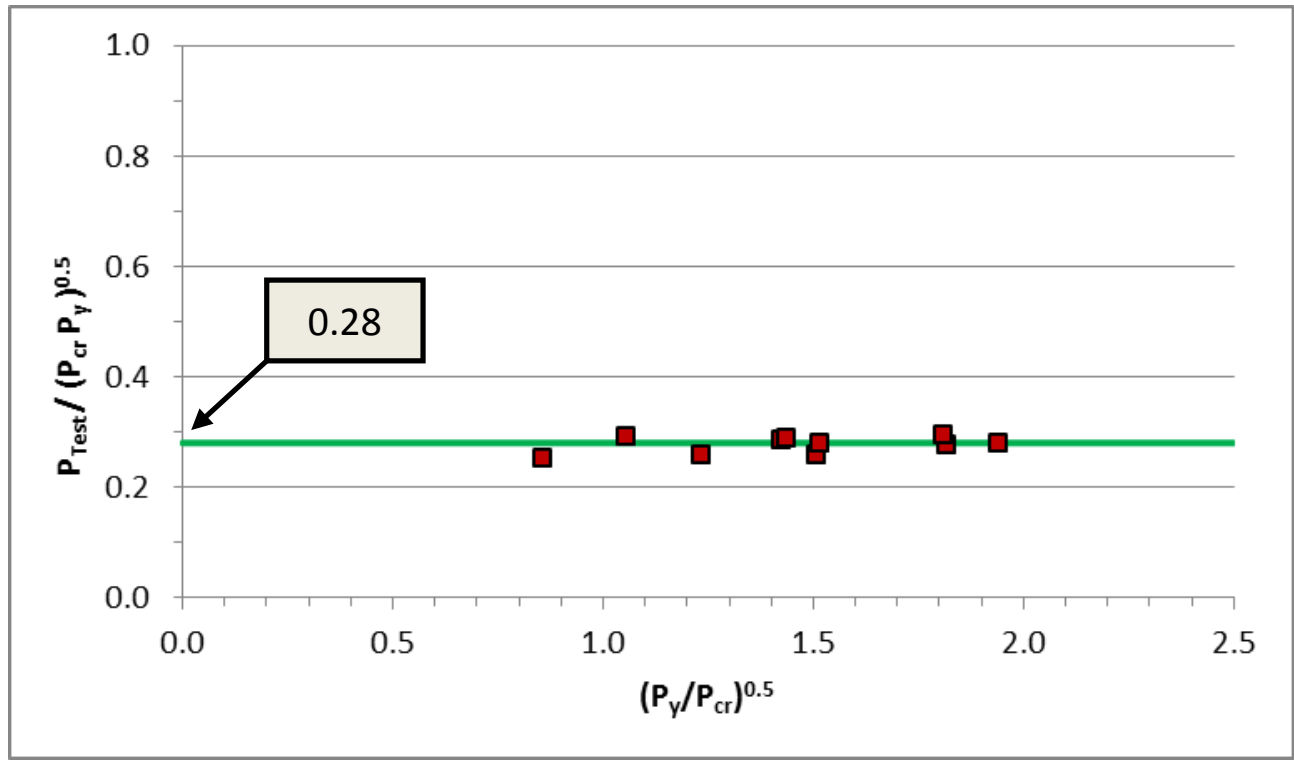

(b) ITF load case

Figure 17: Simplified method to predict the web crippling capacities of DuraGal channels 